\title{
Analysis of the 16 May 2015 Tipton, Oklahoma, EF-3 Tornado at High Spatiotemporal Resolution Using the Atmospheric Imaging Radar
}

\author{
ANDREW MAHRE \\ Advanced Radar Research Center, and School of Meteorology, Norman, Oklahoma \\ JAMES M. KURDZO AND DAVID J. BODINE \\ Advanced Radar Research Center, Norman, Oklahoma \\ CASEy B. GRifFin AND Robert D. PALMER \\ Advanced Radar Research Center, and School of Meteorology, Norman, Oklahoma \\ TIAN-YOU YU \\ Advanced Radar Research Center, and School of Electrical and Computer Engineering, Norman, Oklahoma
}

(Manuscript received 7 September 2017, in final form 20 April 2018)

\begin{abstract}
In this study, data collected by the Atmospheric Imaging Radar (AIR) are analyzed in conjunction with WSR-88D data (KFDR) for a tornado near Tipton, Oklahoma, on 16 May 2015. The analysis presented herein utilizes PPIs from both radars, polarimetric data from KFDR, time-height plots from the AIR, and a ground-based velocity track display (GBVTD) analysis. This study is novel in that it uses high-resolution mobile radar data (update time of 6-7 s) in tandem with polarimetric data from KFDR in order to identify possible areas of debris, including a debris ring contained within the outer vortex circulation. Leveraging the high spatiotemporal resolution of the AIR with the polarimetric capability of KFDR leads to analysis of reflectivity distributions, debris lofting, kinematic changes, and oscillations in tornado intensity during a portion of the mature stage of the tornado, with a particular focus on the relationship between changes in the reflectivity field and dynamical changes around the tornado. Debris is lofted in a high-reflectivity concentric ring of increasing radius and height around the tornado over several minutes, within the outer weak-echo hole (WEH). Simultaneously, debris lofting and asymmetric reflectivity distribution around the WEH coincide with changes in vortex tilt on multiple occasions. In one instance, hydrometeor fallout appears to precede a possible descending reflectivity core. Using the GBVTD results, near-surface convergence intensifies at the same time and location as when the debris ring is lofted. Additionally, strengthening of the tornado via multiple modes of vertical evolution (i.e., bottom-up intensification over time vs simultaneous intensification throughout the lowest few hundred meters) is observed.
\end{abstract}

\section{Introduction}

With the proliferation of mobile Doppler radars into the forefront of tornado analysis, high spatiotemporal resolution radar data have proved invaluable in diagnosing tornado and mesocyclone characteristics (e.g., Wurman and Gill 2000; Bluestein et al. 2003; Beck et al.

Supplemental information related to this paper is available at the Journals Online website: https://doi.org/10.1175/MWR-D-17-0256.s1.

Corresponding author: Andrew Mahre, andrew.mahre@ou.edu
2006; Tanamachi et al. 2007; French et al. 2013; Wurman and Kosiba 2013; Wakimoto et al. 2016; Kurdzo et al. 2017). Within the growing fleet of mobile radars, several possess the capability to collect such high-resolution data, where each system offers unique advantages in terms of resolution, frequency, and polarimetric capabilities (Wurman and Randall 2001; Weiss et al. 2009; Bluestein et al. 2010; Isom et al. 2013; Pazmany et al. 2013; Bluestein et al. 2014). One use of high-resolution radar data at close range has been derivation of an approximated three-dimensional wind field around a tornado using the ground-based velocity track display 
(GBVTD) method (Lee et al. 1999; Bluestein et al. 2003). Previous GBVTD studies have used mobile radar data from close range to analyze primary and/or secondary circulations (Bluestein et al. 2003; Lee and Wurman 2005; Tanamachi et al. 2007; Wurman et al. 2007; Bluestein et al. 2007b; Kosiba and Wurman 2010; Wakimoto et al. 2012; Tanamachi et al. 2013).

Mobile radar data can also be used to study debris processes if polarimetric weather radar data are available. Debris processes can manifest themselves in radar observations in several ways and can impact tornado dynamics. For example, debris presence at low levels can reduce tornado wind speeds and alter vertical pressure gradients through drag-induced momentum transfer (Lewellen et al. 2008; Bodine et al. 2016a) and can lead to an underestimation of radar-derived wind speed due to drag acting on debris, which tends to dominate the Doppler spectrum (Dowell et al. 2005; Wurman and Alexander 2005). Additionally, larger debris is typically centrifuged away from the vortex axis at lower heights, while smaller debris is more easily lofted due to smaller terminal fall speeds (Dowell et al. 2005), which can also bias velocity estimates.

Debris centrifuging can manifest itself as a weak-echo hole (WEH; Fujita 1981; Wurman et al. 1996; Wurman and Gill 2000; Dowell et al. 2005), which is a reflectivity minimum in the center of the tornado, and is generally surrounded by an annulus of higher reflectivity. The WEH is believed to form as a result of debris centrifuging effects (Dowell et al. 2005; Bodine et al. 2016b), but divergence within the central downdraft may also contribute to its formation (Wurman et al. 1996; Bodine et al. 2016a). Tanamachi et al. (2012) suggest that the bottom portion of the WEH may be caused by debris centrifuging effects, while aloft in the WEH, the cause may be related to a narrow, intense updraft at the vortex center. Within the WEH, an inner ring of high reflectivity that is most likely associated with debris may be present. While previous studies have examined debris rings and weak-echo columns (WECs; Wurman and Gill 2000; Wakimoto et al. 2011; Wurman et al. 2013; Houser et al. 2015; Wakimoto et al. 2015), there is a dearth of observational studies that examine the formation and dissipation time scales of debris rings and their kinematic relationships using high-temporal-resolution radar data. Because debris may only reside within the tornado for a few tens of seconds or less (Dowell et al. 2005), high-temporal-resolution radar data are needed to observe debris processes. The Atmospheric Imaging Radar (AIR) has previously been used to study threedimensional reflectivity distribution evolution (Kurdzo et al.2017), although potential debris presence could not be determined due to a lack of polarimetric capability.
The purpose of this study is to use data obtained by the AIR (Isom et al. 2013; Kurdzo et al. 2017) to perform an analysis of the 16 May 2015 tornado near Tipton, Oklahoma. Following a similar procedure to many previous studies, primary and secondary circulations are derived via the GBVTD method (Lee et al. 1999; Bluestein et al. 2003; Lee and Wurman 2005; Bluestein et al. 2007b; Tanamachi et al. 2007; Kosiba et al. 2008; Kosiba and Wurman 2010; Tanamachi et al. 2013). This effort aims to relate debris processes with primary and secondary circulations derived from the GBVTD. This study is novel in that a mobile radar-based GBVTD is used in conjunction with WSR-88D polarimetric data to assess possible debris presence because the AIR transmits only horizontal polarization. Data are used from both radars in order to capitalize on both the high spatiotemporal resolution of the AIR and the polarimetric capability of KFDR, although the scattering characteristics between the two radars vary due to the difference in transmit frequency (e.g., Dolan and Rutledge 2009; Snyder et al. 2017). Leveraging the high spatiotemporal resolution and simultaneous range-height indicators (RHIs) of the AIR is crucial, as debris lofting and major kinematic changes to the tornado can occur on the order of a few tens of seconds (Wurman and Kosiba 2013; French et al. 2014; Wakimoto et al. 2015; Kurdzo et al. 2017), as exemplified by three-dimensional representations of AIR reflectivity data (see Fig. $\mathrm{S}^{1}$ in the online supplemental material).

This paper is divided into two main foci. First, analysis of how a ring of higher reflectivity (located between the vortex axis and the outer vortex circulation) is lofted is interrogated via time-height plots and axisymmetric analysis of both AIR and KFDR data. This focus aims to determine the scatterer types (debris vs hydrometeors) within the reflectivity maximum in a rigorous manner by comparing collocation between enhanced reflectivity from the AIR and lowered correlation coefficient from KFDR. Additionally, the ascending reflectivity ring (which is believed to be associated with debris) is tracked in time. The second focus of the paper is on analysis of the dynamics of the tornado using high-temporal-resolution volumetric data. Because of the short temporal time scales for kinematic changes in tornadoes and tornadogenesis (Wurman and Kosiba 2013; French et al. 2014; Wakimoto et al. 2015; Kurdzo et al. 2017), high-temporal-resolution observations of tornadoes are essential. Few studies have examined tornado-scale velocity signatures at extremely high temporal resolution $(<10 \mathrm{~s})$, and thus a larger sample size of

\footnotetext{
${ }^{1}$ The green, orange, and red three-dimensional isosurfaces represent 32.5, 40, and $47.5 \mathrm{~dB} Z$, respectively.
} 
rapid-scan cases needs to be examined. In this study, periodicities and changes in tornado tilt are examined, and similarities and differences are compared to past studies. A periodicity in tornado couplet intensity is noted via a time-height plot, and changes in tornado tilt are tracked. Additionally, a possible correlation between changes in tornado tilt and storm-scale processes [i.e., precipitation fallout and a subsequent rear-flank gust front surge (RFGFS)] is postulated. These two foci are tied together via a GBVTD-based analysis to explore how kinematic processes affected debris lofting. This paper attempts to answer the following questions:

- Near the surface, was the reflectivity structure (i.e., a reflectivity ring) lofted in a particular pattern?

- Was there low-level lift associated with a lofted reflectivity ring within the outer WEC?

- Was the lofted reflectivity ring associated primarily with hydrometeors or debris?

- How did reflectivity distribution around the WEC, and a possible descending reflectivity core (DRC), affect the track of the WEC?

- What periodicities in tornado strength are observed throughout the analyzed portion of the mature stage of the tornado, as determined by tornadic vortex signature (TVS) intensity?

- Are these periodicities observed simultaneously or nonsimultaneously through the column?

In this study, it is shown that the onset of low-level surface convergence coincided with a ring of higher reflectivity (debris) being lofted within the outer WEC. Simultaneously, a DRC caused track changes (and, by extension, changes in vortex tilt) to the WEC. These observations underscore the connection between changes in the reflectivity field and dynamical changes in the flow structure of the tornado. Additionally, a periodicity in tornado intensity is observed to occur with multiple modes of vertical evolution, although no corresponding change in the reflectivity distribution appears to coincide with this periodicity.

\section{Case overview, instrumentation, and methods}

\section{a. Case overview}

The tornado studied herein initiated via a supercell along a north-south-oriented dryline on 16 May 2015 and was rated as an EF-3 by the National Weather Service (NWS). The tornado was initially located approximately $3 \mathrm{~km}$ south of the Red River, in northern Hardeman County (Texas). Approximately halfway through the life cycle of the tornado, the AIR collected radar data on the tornado as it passed near the town of
Tipton, Oklahoma. The duration of the tornado was approximately $85 \mathrm{~min}$, while the AIR collected data on the mature stage of the tornado for $32 \mathrm{~min}$ (Fig. 1). The analysis presented herein focuses on a window of approximately $5 \mathrm{~min}$ during the mature stage of the tornado because of major kinematic changes that occurred around this time. During this analysis period, the AIR was positioned approximately $12-14 \mathrm{~km}$ from the tornado. Data from the AIR have been combined with data from KFDR in order to analyze the tornado during part of its mature phase using both polarimetric and nonpolarimetric radar variables.

\section{b. Atmospheric Imaging Radar}

In recent years, advantages gained by agile beam steering and beam multiplexing (and, by extension, highertemporal-resolution radar data) have been noted for both research and operations (Weber et al. 2007; Yu et al. 2007; Zrnić et al. 2007; Heinselman and Torres 2011; Wilson et al. 2017). The AIR, designed and built by faculty, staff, and students at the University of Oklahoma Advanced Radar Research Center (ARRC), is a mobile, X-band, phased array imaging radar that is capable of providing high spatiotemporal resolution radar data (Isom et al. 2013). The AIR is the first imaging weather radar used for meteorological applications; however, imaging has since been adapted by other radar systems (e.g., Wu et al. 2013; Yoshikawa et al. 2013; Adachi et al. 2016; Kashiwayanagi et al. 2016). Because the AIR is an imaging radar, a fan beam is transmitted in the vertical dimension $\left(1^{\circ}\right.$ wide in azimuth and $20^{\circ}$ wide in elevation, with $1.1^{\circ}$ resolution in elevation while using Fourier beamforming), allowing for collection of high-temporal-resolution data via digital beamforming (DBF). Thus, no steering (either mechanical or electronic) is necessary in elevation, while mechanical steering of the horizontally polarized beam is performed in azimuth. Such a configuration allows for simultaneous RHIs to be sampled at all times.

For the purposes of this study, AIR data are oversampled to $0.5^{\circ}$ in azimuth and $0.5^{\circ}$ in elevation. The transmitted pulse uses nonlinear frequency modulation (NLFM) with $5 \mathrm{MHz}$ of bandwidth and minor tapering, resulting in 37.5-m range resolution, oversampled to $30 \mathrm{~m}$ (Kurdzo et al. 2014). The scanning mode during data collection for the Tipton tornado used a 314- $\mu \mathrm{s}$ pulse repetition time (PRT) and a 5.25- $\mu$ s pulse length. This yields a Nyquist velocity of $25 \mathrm{~m} \mathrm{~s}^{-1}$; velocity data are dealiased manually during postprocessing. With a $105^{\circ}$ sector, volumetric updates are obtained every $6-7 \mathrm{~s}$. On the array of receive elements, element calibration is performed using a method based on the spatial correlation properties of ground clutter, which is outlined in Attia and Steinberg (1989). 


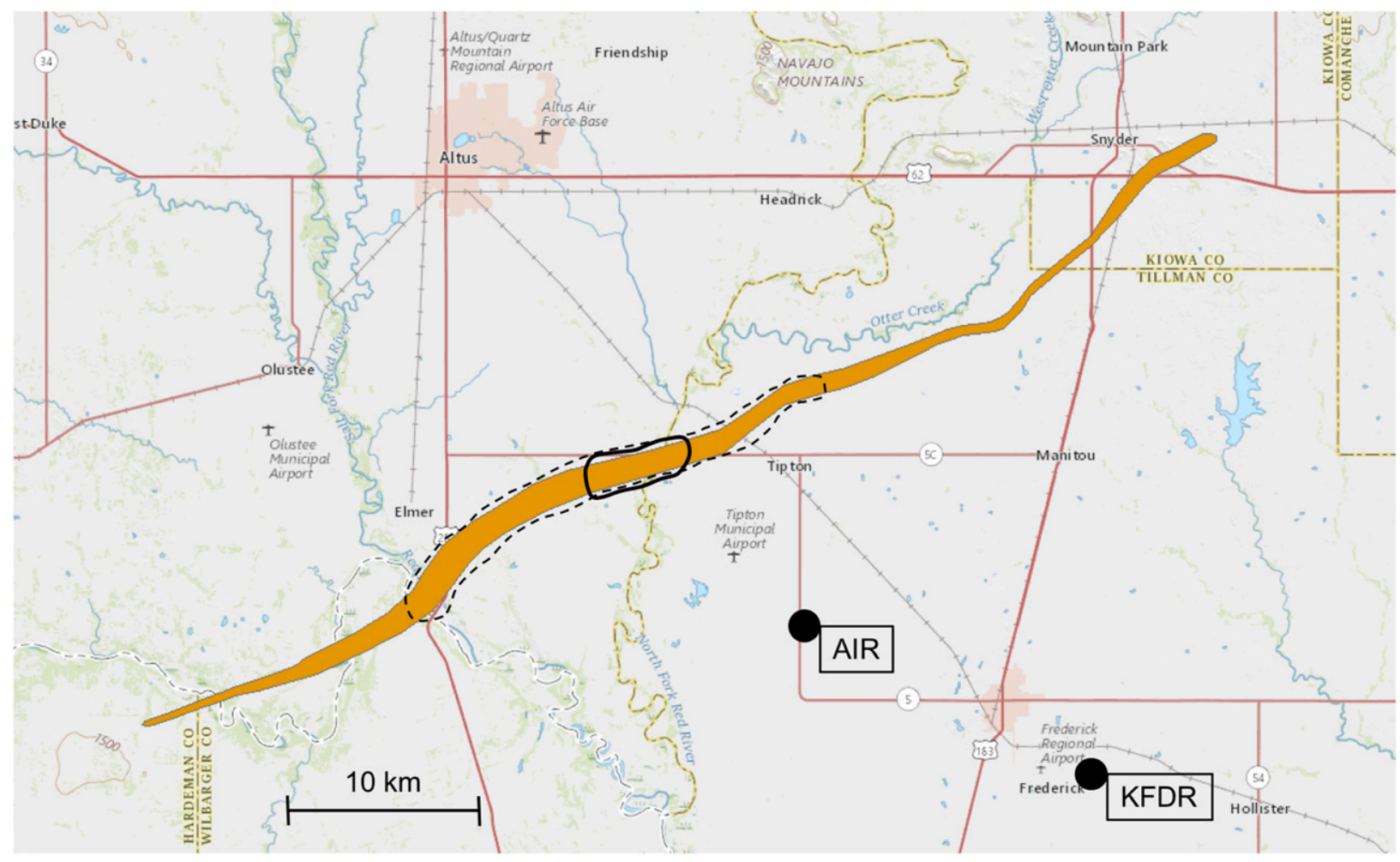

FIG. 1. A diagram showing the location of the AIR and the location of KFDR, with the tornado damage path in orange. The dashed black line shows an approximate portion of the tornado path for which the AIR collected data, and the solid black line shows the $\sim 5$ min section that was analyzed most heavily.

In total, 32 channels of in-phase/quadrature (I/Q) data are used to perform Fourier (nonadaptive) beamforming by linearly applying complex weights to each receiving element (Skolnik 2008). One direct consequence from the use of DBF on receive is greater flexibility in sampling choice. The use of a fan beam allows for simultaneous vertical cross sections through the area of interest, which can allow for analysis that does not need to account for either horizontal or vertical advection between elevations (Kurdzo et al. 2017; Mahre et al. 2017). In this study, this advantage is leveraged to draw conclusions regarding the primary and secondary circulations about the central axis of the tornado, as well as azimuthally averaged variables about the vortex center.

\section{c. Polarimetric data}

To ascertain whether or not a region of high reflectivity might contain debris, collocation between lowered copolar correlation coefficient $\rho_{\mathrm{hv}}$ and increased reflectivity factor $Z_{H}$ is studied. For debris identification, $\rho_{\text {hv }}$ is used instead of other polarimetric variables such as differential reflectivity $Z_{\mathrm{DR}}$ because of the biases present in $Z_{\mathrm{DR}}$ due to both rain and differential attenuation (Bluestein et al. 2007a; Schultz et al. 2012; Bodine et al.
2014). Collocation among lowered copolar correlation coefficient $\left(\rho_{\mathrm{hv}}<0.8\right)$, increased $Z_{H}\left(Z_{H}>40 \mathrm{~dB} Z\right)$, and a velocity couplet would be consistent with a tornadic debris signature (TDS; e.g., Ryzhkov et al. 2002, 2005; Kumjian and Ryzhkov 2008; Palmer et al. 2011; Bodine et al. 2013; Snyder and Ryzhkov 2015; Houser et al. 2016). Because of the close proximity of KFDR to the tornado, azimuthally averaged moments from the two radars can be compared $\left(Z_{H}\right.$ from the AIR is compared with $\rho_{\text {hv }}$ from KFDR). This comparison is possible only because of the serendipitous proximity between KFDR and the AIR (for a comparison of characteristics among several mobile radar systems, see Table 1 of Kurdzo et al. 2017). To compare the AIR and KFDR datasets, the large difference in time between successive scans (6-7 s for the AIR, $\sim 300 \mathrm{~s}$ for KFDR) must be accounted for. To address this, each AIR scan was paired with a KFDR scan by finding the closest AIR scan to the average time of the scans with elevation angles less than $4^{\circ}$ from KFDR.

\section{d. Ground-based velocity track display}

The concept of velocity track display (VTD) was originally developed for single-Doppler wind retrieval 
around tropical cyclones from airborne radar data (Lee et al. 1994). This was later modified by Lee et al. (1999) into GBVTD. In addition to primary (tangential) circulation around the vortex, radial (Bluestein et al. 2003, 2007b; Tanamachi et al. 2007; Wurman et al. 2007) and vertical (Lee and Wurman 2005; Weiss et al. 2007; Kosiba and Wurman 2010; Wakimoto et al. 2012) velocities can be estimated around the central axis of a tornado by using the GBVTD method.

The GBVTD concept relies on the assumption of azimuthal symmetry about a vertical axis through the tornado center. Despite occasional azimuthal asymmetry in reflectivity, the velocity field around the vortex axis is quite symmetric. Although the velocity field is mostly symmetric, asymmetries in the velocity field may negatively influence the GBVTD analysis. However, these asymmetries are minor, and given the qualitative nature of the GBVTD analysis herein, it is unlikely that the minor velocity asymmetries significantly alter the conceptual interpretation of the GBVTD results.

A representative example of the dealiased velocity field is shown in Fig. 2. For each PPI, a center point of the vortex is chosen subjectively using the velocity couplet. By assuming symmetry about a vertically oriented axis, secondary circulations $(u$ and $w$, referring to the vortex-relative radial and vertical velocities, respectively) can be estimated [see Figs. 1 and 2 in Lee et al. (1999) for an example of how this is calculated]. This study calculates mean $u$ about a given annulus [i.e., the wavenumber- 0 component using methods outlined in Dowell et al. (2005)]; the distance from the AIR to the vortex precludes higher wavenumber analysis, which can be achieved with improved low-level data (Lee and Wurman 2005; Liou et al. 2006; Tanamachi et al. 2007; Jou et al. 2008; Potvin et al. 2009; Wakimoto et al. 2012; Nolan 2013; Tanamachi et al. 2013). Vertical velocity $w$ can be calculated by assuming incompressibility (i.e., $\nabla \cdot \mathbf{u}=0)$ throughout the layer and impermeability at the surface and integrating divergence upward throughout the layer. In this study, however, finescale estimates of $w$ are not calculated due to the distance from the AIR to the vortex, which degrades confidence in mass flux estimation. Despite the distance from the tornado to the radar, axisymmetric convergence and divergence is calculated, which can be used as a proxy for $w$ under certain circumstances. This will be described in further detail in a later section.

Although the GBVTD method can derive secondary circulations, debris centrifuging and a lack of low-level velocity data can lead to errors in analysis in $u$ and $w$, respectively (Dowell et al. 2005; Wakimoto et al. 2012; Nolan 2013). To account for debris centrifuging in $u$, a correction term has been applied to the GBVTD based on Eq. (3.1) in Nolan (2013). This correction accounts for the estimated maximum centrifuging velocity. For this study, a maximum centrifuging velocity of $6 \mathrm{~m} \mathrm{~s}^{-1}$ was used. Since scatterer characteristics in tornadoes are unknown (Bodine et al. 2016b), a qualitative analysis of the secondary circulations was conducted for this case (not shown). The result was that maximum centrifuging velocity values within a typical range of maximum centrifuging velocity $\left(4-20 \mathrm{~m} \mathrm{~s}^{-1}\right)$ yielded similar $u$ fields. Thus, it is believed that $6 \mathrm{~m} \mathrm{~s}^{-1}$ is sufficient to account for debris centrifuging in this study.

The issue of low-level radar coverage is not entirely correctable, as beam height increases as distance to the radar increases (Doviak and Zrnić 2006). With a minimum range of $12 \mathrm{~km}$ to the radar from the vortex center, most traditional pencil-beam radars would not be able to sample the low levels effectively, unless the volume coverage pattern (VCP) was modified to scan below the typical base scan of $0.5^{\circ}$ in elevation. For example, if the lowest sampled elevation angle during the scan were $0.5^{\circ}$, the lowest $115 \mathrm{~m}$ of the vortex would not be sampled. As shown by Nolan (2013), neglecting the lowest levels in a GBVTD analysis (especially below $80 \mathrm{~m}$ ) can lead to large errors in estimated vertical velocities due to poor mass flux estimation.

The AIR can theoretically avoid this pitfall by the use of DBF on receive. By transmitting a fan beam in elevation, choice of beamformed elevation angles can be made during postprocessing. However, despite beamforming at $0.2^{\circ}$ in elevation for this case (approximately

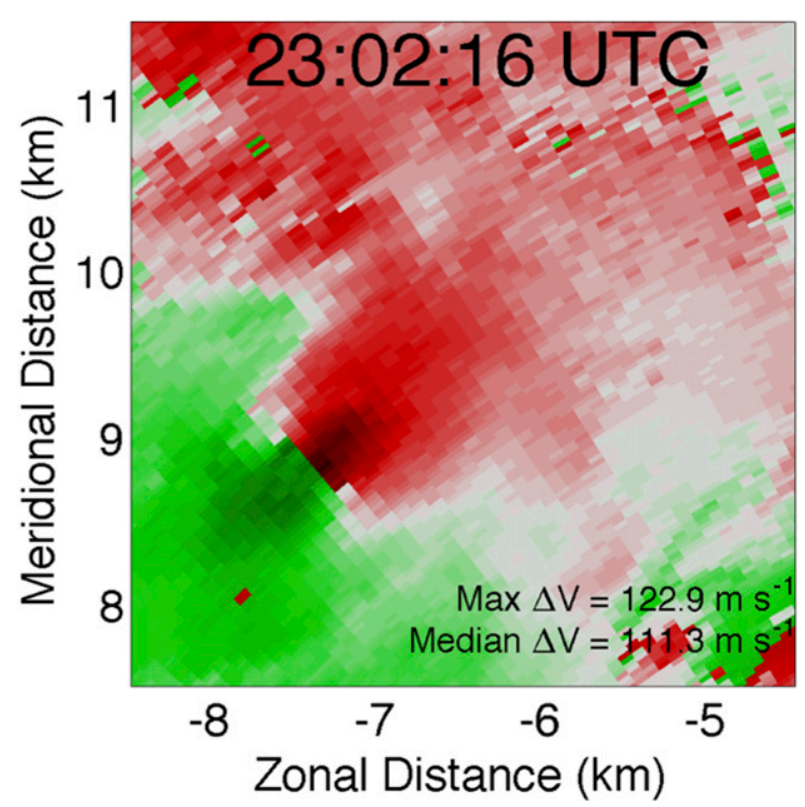

FIG. 2. A representative example of the velocity field around the tornado at $3^{\circ}$ in elevation. Maximum gate-to-gate shear and median gate-to-gate shear $(\Delta V)$ along the zero-isodop are listed. 
TABLE 1. An index of the times referenced in the text (times A-D).

\begin{tabular}{ccl}
\hline \hline Time letter & Time (UTC) & \multicolumn{1}{c}{ Description } \\
\hline $\mathrm{A}$ & $2300: 47$ & Beginning of debris ring deepening \\
$\mathrm{B}$ & $2301: 14$ & Continued ring deepening/lofting, beginning of bottom-up intensification mode \\
$\mathrm{C}$ & $2301: 42$ & Enhanced surface convergence, upward motion $\sim 400 \mathrm{~m}$ from vortex center \\
$\mathrm{D}$ & $2302: 16$ & Vortex tilted $30^{\circ}$, inward angular momentum erosion, left turn in mesocyclone track \\
\hline
\end{tabular}

$60 \mathrm{~m}$ above ground level at the tornado), a lack of sufficient confidence in $w$ values precludes any strong claims about its implications. Because the native elevation beamwidth is $1.1^{\circ}$, the beams at $0.2^{\circ}$ and $0.5^{\circ}$ are not truly independent. Additionally, a large portion of the beam at $0.2^{\circ}$ in elevation would be pointing into the ground. Thus, only radial convergence is calculated in this study, where "radial" implies motion toward or away from the central vortex axis. From the convergence/divergence field (where divergence corresponds to negative convergence), general vertical motion patterns can be implied without making claims regarding finescale detail in $w$.

\section{e. Axisymmetric analyses}

In addition to deriving secondary circulations about a chosen center point, radar variables within an annulus can be averaged to create a height-radius axisymmetric plot. In this study, an annulus size of $50 \mathrm{~m}$ is used. These plots are used in conjunction with AIR-based, GBVTD-derived secondary circulations, where either $u$ or convergence/divergence contours are overlaid on axisymmetrically averaged radar variables. Using data from the AIR, axisymmetric plots of reflectivity and angular momentum are created. Additionally, KFDR is used to create axisymmetric plots of correlation coefficient $\rho_{\mathrm{hv}}$. However, there is a large disparity in temporal resolution between axisymmetric plots from the AIR and from KFDR that must be considered. Overall, the axisymmetric plots allow for qualitative observations of trends in variables with radius and height within various volumes.

\section{Results}

On 16 May 2015, the AIR collected data 12-14 km from the tornado. The AIR was positioned approximately $8 \mathrm{~km}$ south of Tipton, Oklahoma (Fig. 3). While data were collected for $32 \mathrm{~min}$, this study focuses on a $4-5-\mathrm{min}$ window of the mature stage of the tornado, when debris lofting was most prevalent. Additional information about this storm can be found in Kurdzo et al. (2017). Unfortunately, some of the AIR data were contaminated with a grating lobe artifact from a higher elevation (Fig. 3a). Grating lobe artifacts exist on phased array radars if the spacing between elements is greater than half of the transmit wavelength, causing additional mainlobes in the two-way antenna pattern (Skolnik 2001). Grating lobe artifacts are unavoidable on the AIR due to the element spacing $(1.8 \lambda$, where $\lambda$ is the radar wavelength). However, the presence of this artifact is not believed to appreciably affect the analysis presented herein, since high SNR regions are analyzed, and the electric field intensity at the grating lobes is reduced due to convolution with the transmit pattern (Isom et al. 2013).

During this time, a reflectivity maximum in the shape of a toroid (i.e., a doughnut) is present, residing interior to the outer vortex circulation. This maximum first appeared at 2259:59 UTC in the $0.5^{\circ}$ elevation scan from the AIR. The upper edge of this toroid advected upward at approximately $10 \mathrm{~m} \mathrm{~s}^{-1}$ (Fig. 4). As this occurred, the reflectivity maximum began to expand outward into a ringlike shape above $400 \mathrm{~m}$ (above $2^{\circ}$ in elevation; see Fig. 4). A similar ringlike structure has been observed in previous studies (e.g., Wurman and Gill 2000; Bluestein et al. 2007a; Wurman et al. 2010, 2013). In this section, the reflectivity ring evolution and kinematic characteristics of the tornado are discussed.

\section{a. Ring lofting observations}

Kinematic changes of the ring of higher reflectivity can be observed via subjective analysis of PPIs from the AIR (Fig. 4). This reflectivity maximum resembles a toroidal pattern throughout the following few scans. Approximately $14 \mathrm{~s}$ after the reflectivity maximum appears at $2^{\circ}$ in elevation, a similar ring appears in the $3^{\circ}$ elevation angle data, becoming more distinct over time. This ring of higher reflectivity appears at increasing elevations, albeit with lower reflectivity aloft; the lower reflectivity could be due to debris fallout. Leveraging the simultaneous RHIs of the AIR allows for improved observation of this phenomenon.

RHIs through the WEC exemplify vertical ring growth over time (Fig. 5). Creation of simultaneous RHIs is possible through the use of digital beamforming on receive, as described in section $2 \mathrm{~b}$. These RHIs are plotted at 2300:47, 2301:14, and 2301:42 UTC (times A-C, respectively, see Table 1). In each RHI, the WEC can be observed at approximately $12 \mathrm{~km}$ in range to the AIR, extending to $4 \mathrm{~km}$ above radar level (ARL). Between 

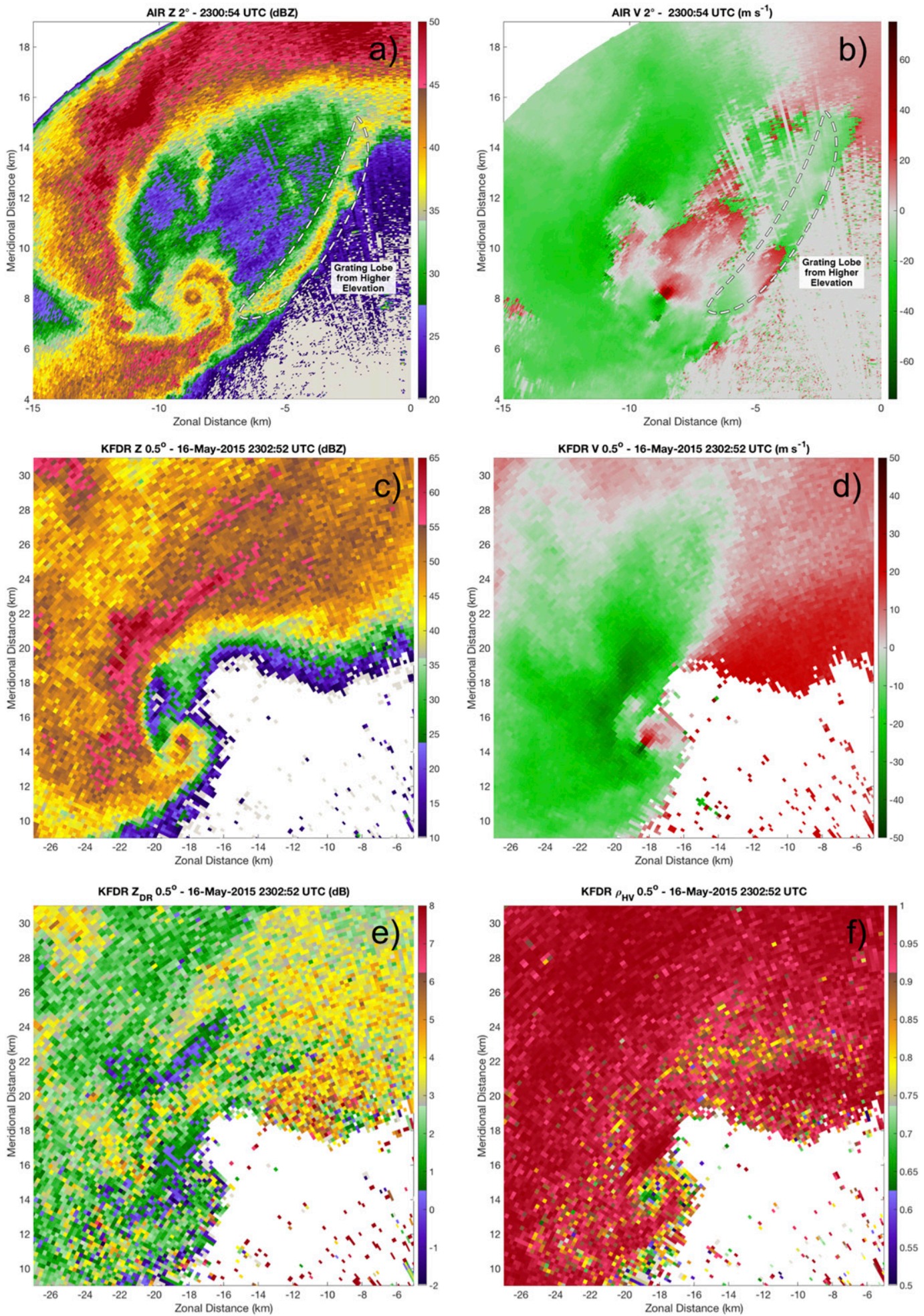

FIG. 3. PPIs from KFDR at 2302:52 UTC and the AIR at 2300:54 UTC. (a)-(d) Reflectivity factor $Z_{H}$ and radial velocity $v_{r}$ from both the AIR and KFDR. (e),(f) Differential reflectivity $Z_{\mathrm{DR}}$ and copolar correlation coefficient $\rho_{\text {hv }}$ from KFDR. 


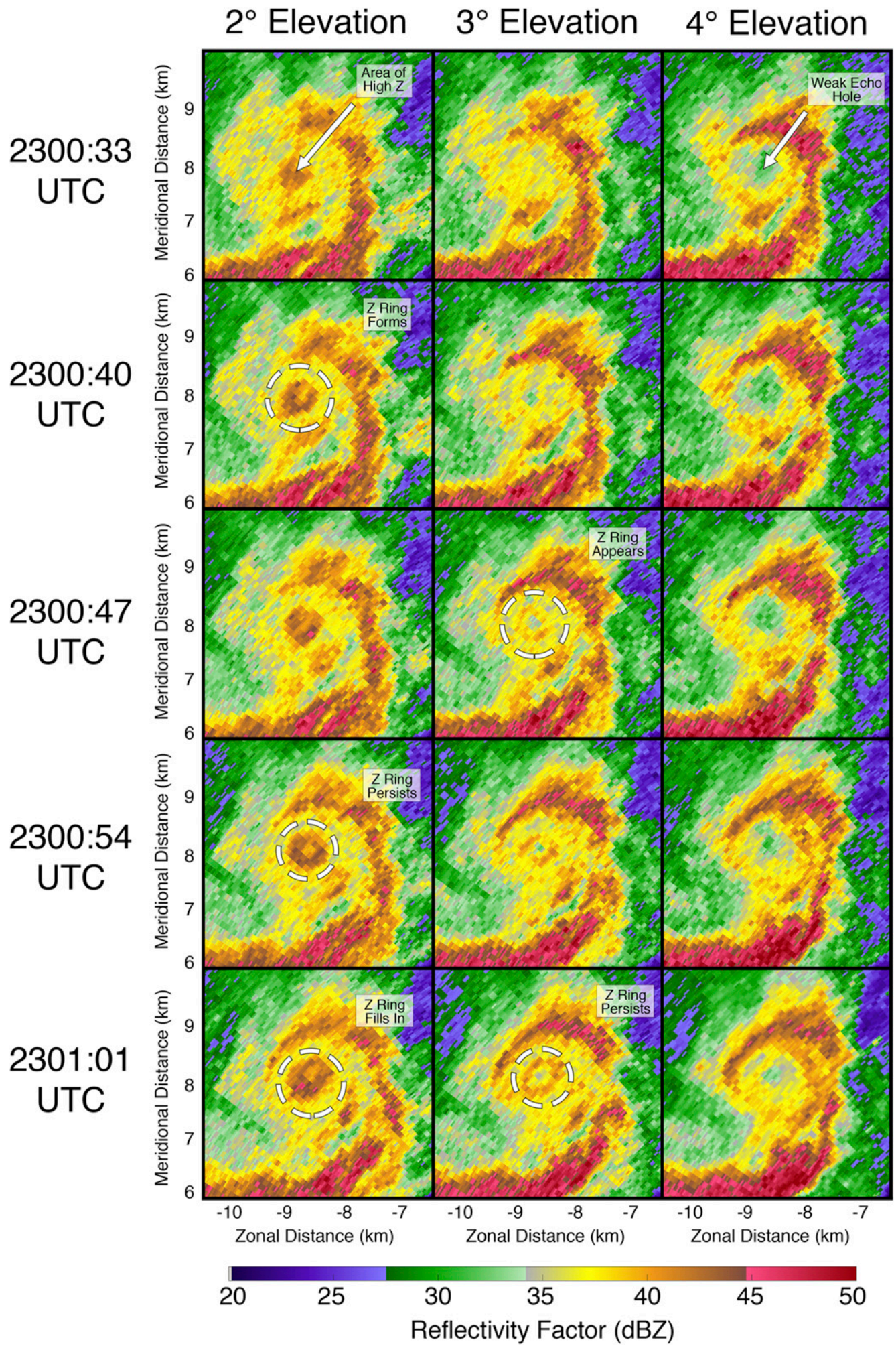

FIG. 4. Reflectivity PPIs (in dBZ) from the AIR at $2^{\circ}-4^{\circ}$ in elevation $(\sim 400-800 \mathrm{~m}$ ARL) over five successive scans. Note the appearance of a reflectivity maximum at $2^{\circ}$ in elevation, as well as a "ring" within the outer $\mathrm{WEH}$ at $2^{\circ}$ and $3^{\circ}$ in elevation, about $14 \mathrm{~s}$ apart. 

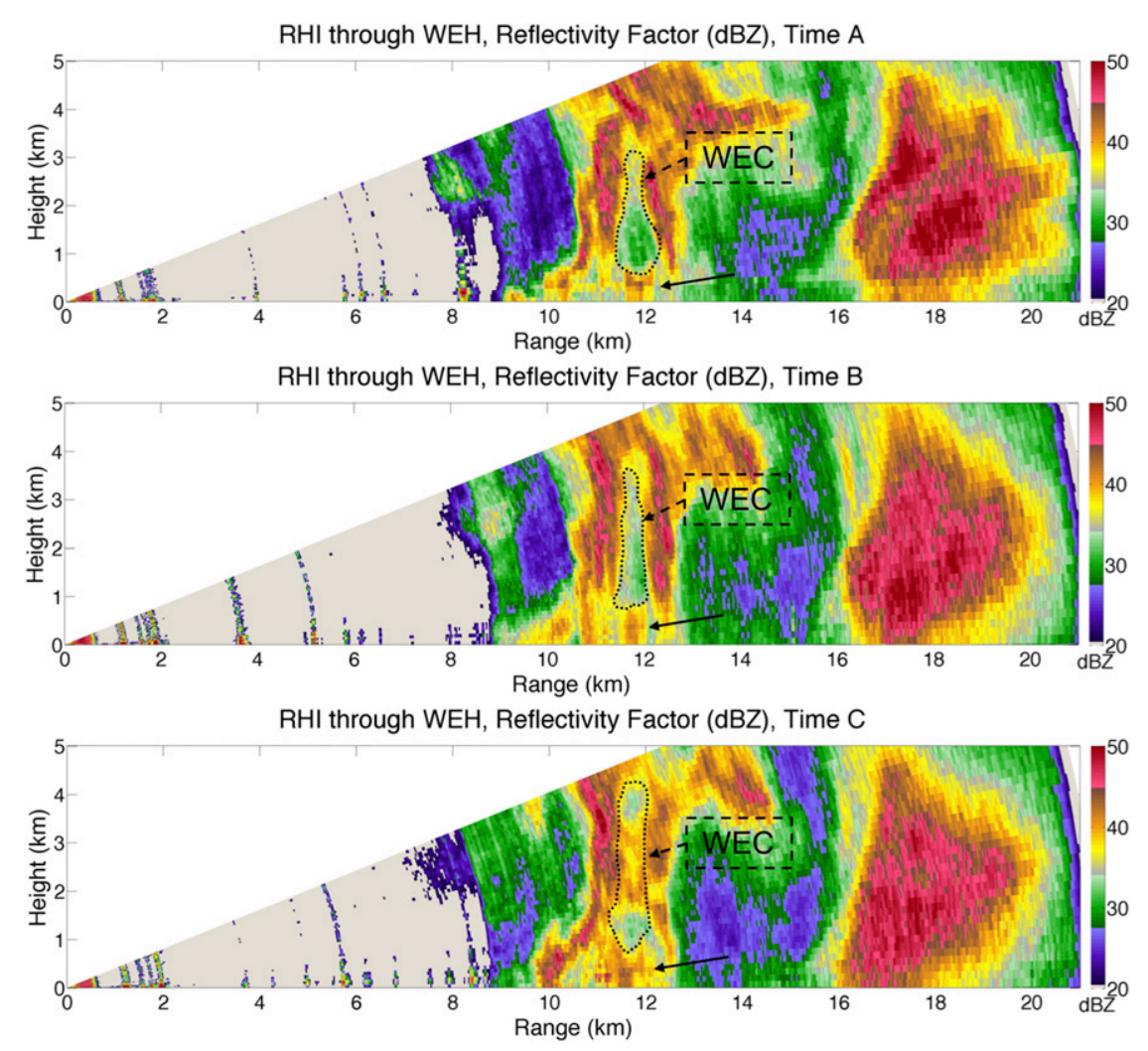

FIG. 5. RHIs through the WEC at times A, B, and C (2300:47, 2301:14, and 2301:42 UTC). The outline of the WEC is denoted by the dashed line. The lofted region of higher reflectivity is directly underneath the WEC, denoted by the solid arrow.

times $\mathrm{A}$ and $\mathrm{C}$, the ringlike region of higher reflectivity expands radially around the central axis of the WEH and grows in height, with a depression near the center of the debris column top.

To examine the ring expansion throughout the AIR volume scan, axisymmetric (relative to the vortex axis) data are plotted from 2300:47 to 2302:16 UTC. The center of the vortex was determined at each elevation via subjective analysis of the velocity couplet. AIR-based reflectivity is shown in the left-hand column of Fig. 6. Data shown are from 2300:47, 2301:14, 2301:42, and 2302:16 UTC (times A-D, respectively). To obtain polarimetric information, data from KFDR are used to create similar axisymmetric plots of $\rho_{\mathrm{hv}}$, shown in the right-hand column of Fig. 6. Because of increased range from the radar, the lowest beam height available from KFDR is significantly higher than lowest beam heights from the AIR. Thus, low-level $\rho_{\text {hv }}$ data are missing from Fig. 6. As an overlay in Fig. 6, radial convergence with respect to the vortex axis, derived from the GBVTD, is plotted as contours.

Lofting of a region of higher reflectivity is shown in the AIR scans in the left-hand column of Fig. 6. The topleft panel (time A) shows that the region of higher reflectivity is mainly confined to the nearest $\sim 350 \mathrm{~m}$ in radius and the lowest $700 \mathrm{~m}$ in height during the first analyzed scan. The reflectivity plots at times B and C in Fig. 6 show this region of higher reflectivity expanding with both radius and height. Finally, at time D, the AIR reflectivity field shows a marked region of lofting originating from the central reflectivity region $(200-400 \mathrm{~m}$ in height and $0-200 \mathrm{~m}$ in radius) and expanding upward in height and outward in radius. This upward/outward pattern in reflectivity is consistent with the appearance of a reflectivity ring that appears to grow radially with height, as well as with previous observations (e.g., Wurman and Gill 2000) and a conceptual model shown in Griffin et al. (2017).

Observations of correlation coefficient from KFDR (Fig. 6) aid in addressing the question of debris presence within the region of high reflectivity. In the top three rows of the right-hand column of Fig. 6, the same KFDR $\rho_{\mathrm{hv}}$ underlay is shown in the right-hand column, as that scan is the closest match to these three AIR scans. The bottom-right panel of Fig. 6, however, shows the subsequent WSR-88D scan, as this most closely matches up with the AIR scan in the bottom-left panel of Fig. 6. 

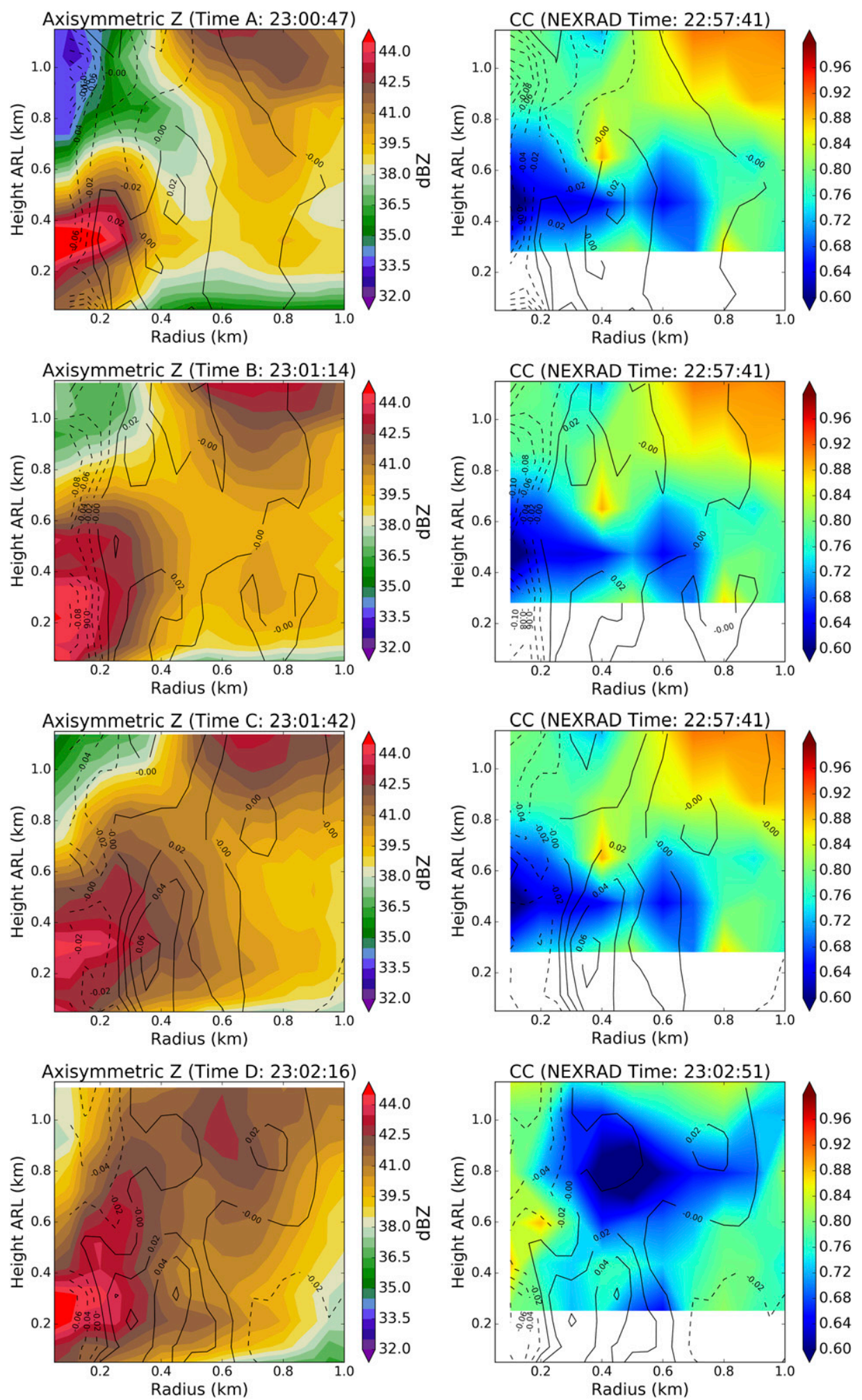

FIG. 6. Axisymmetric plots at times A-D (2300:47, 2301:14, 2301:42, and 2302:16 UTC) showing both (left) an AIR-based reflectivity underlay (in $\mathrm{dBZ}$ ) and (right) a KFDR-based correlation coefficient underlay at the closest-matched NEXRAD scan. The solid contours represent AIR-derived radial convergence in $\mathrm{s}^{-1}$, such that negative values (dashed contours) indicate radial divergence. 
At times A-C, a region of low $(<0.75)$ correlation coefficient is confined to approximately the same region as the higher $(>40 \mathrm{dBZ})$ reflectivity, indicative of a TDS (Kumjian and Ryzhkov 2008). At time D, the region of lower correlation coefficient has moved upward (from 500 to $800 \mathrm{~m}$ in height) and radially outward (centered at $450 \mathrm{~m}$ in radius, where before it was confined to the nearest few hundred meters in radius). The similar upward/outward movement of the region of lowered correlation coefficient coincides with the upward/outward movement of the reflectivity ring. This suggests that the higher reflectivity region comprises largely debris, and scatterers within the circular region of high reflectivity near the surface are advected outward as they are lofted, forming the debris ring.

The WEC pattern in Fig. 5 resembles the transition between a one-cell and two-cell vortex shown in Fig. 1a of Trapp (2000), especially at times A and B. This comparison is made not only because of the similarity between the WEC structures, but also because of the implied vortex structure and vertical motion. At times $\mathrm{C}$ and $\mathrm{D}$, the lowest $600 \mathrm{~m}$ in height contains a region of strong radial convergence centered at approximately $400 \mathrm{~m}$ in radius away from the tornado center, as determined by the wavenumber- 0 component of the GBVTD (Fig. 6). At time C, the convergence has increased, compared to time $\mathrm{B}$, with convergence exceeding $0.04 \mathrm{~s}^{-1}$ over a large area at both times C and D. Assuming incompressibility and impermeability at the surface, general inferences can be suggested about the overall vertical motion pattern if it is assumed that the wind field does not change drastically in the lowest $60 \mathrm{~m}$ (below the lowest beamformed level). The radial convergence in the low levels should imply upward vertical motion aloft at these radii. Conversely, lowlevel divergence (convergence $<0$; e.g., the lowest $400 \mathrm{~m}$ ARL and $<200 \mathrm{~m}$ in radius at time D) should correspond to downward vertical motion. Thus, the implied flow characteristics in the Tipton tornado (central downdraft and concentric updraft) at time D are consistent with the two-cell vortex model (Sullivan 1959; Leslie and Snow 1980; Nolan and Farrell 1999). The lack of low-level data, however, precludes any finescale or detailed analysis of vertical motion (Nolan 2013). The radius of maximum radial convergence moves outward (away from the vortex center) with time and is collocated in radius with the outer edge of the debris ring. A radial outward shift in this updraft could explain the ring expansion (both radially and vertically), as debris trajectories should follow the wind pattern, although debris centrifuging may also explain the ring expansion.

To examine the kinematic ring changes from a statistical perspective, a time-height analysis of median $Z_{H}$ is presented (Fig. 7). For each scan, PPIs are analyzed at $0.5^{\circ}$ sampling in elevation, and the median reflectivity factor within the tornadic vortex is plotted (background color of Fig. 7). The lighter swath between the two sets of dots represents the vertical layer over which the inner debris ring is present. The appearance and disappearance of the reflectivity ring are plotted with black dots, where an upper row of dots signifies the initial appearance of the reflectivity ring at a given height, and the bottom row of dots signifies the disappearance of the reflectivity ring at a given height, determined via subjective analysis. The time-height method allows for analysis of the effect of the debris ring on changes in the vertical distribution of reflectivity, as well as the amount of debris being lofted. The median $Z$ within the tornadic vortex is determined by defining a region around the central axis (consistent in size with the radial extent of the outer WEH), keeping the region size constant, and while moving the region to match the tornado motion, calculating the median $Z$. A quantifiable increase in median $Z$ around the tornado while debris lofting occurs is observed via qualitative analysis.

A notable increase in reflectivity factor with height and time coincides with the initial appearance of the upper edge of the reflectivity ring. This region begins around time $\mathrm{A}$ at $400 \mathrm{~m}$ in height and trends upward with time, following the initial appearance of the reflectivity ring by 10-20 s (upper row of dots). While the top edge of the ring coincides with higher $Z_{H}$ in the tornadic vortex, there is no noticeable correlation between the disappearance of the ring and reflectivity factor, although this could be due to recirculation of debris into the convergence zone at the vortex base, similar to that seen in Figs. 10 and 12 in Dowell et al. (2005).

\section{b. Vortex dynamics and storm-scale processes}

\section{1) VORTEX TILT}

To analyze how WEC tilt evolves with time, $3^{\circ}-10^{\circ}$ vortex tilt (relative to the local vertical) was calculated and plotted (overlay in Fig. 8). The tilt was calculated by choosing the center points of the vortex subjectively at $3^{\circ}$ and $10^{\circ}$ in elevation, corresponding to approximately 0.6 and $2 \mathrm{~km} \mathrm{ARL}{ }^{2}$ These elevations were chosen as being representative of the tornado position and mesocyclone position, respectively. Because the distance from the radar to the tornado does not change significantly throughout the analysis period, the change in beam height at a constant elevation angle should not appreciably alter the analysis. To determine the location of the

\footnotetext{
${ }^{2}$ Beam height should be between 588 and $649 \mathrm{~m}$ for $3^{\circ}$ in elevation and between 1935 and $2132 \mathrm{~m}$ for $10^{\circ}$ in elevation (Doviak and Zrnić 2006).
} 


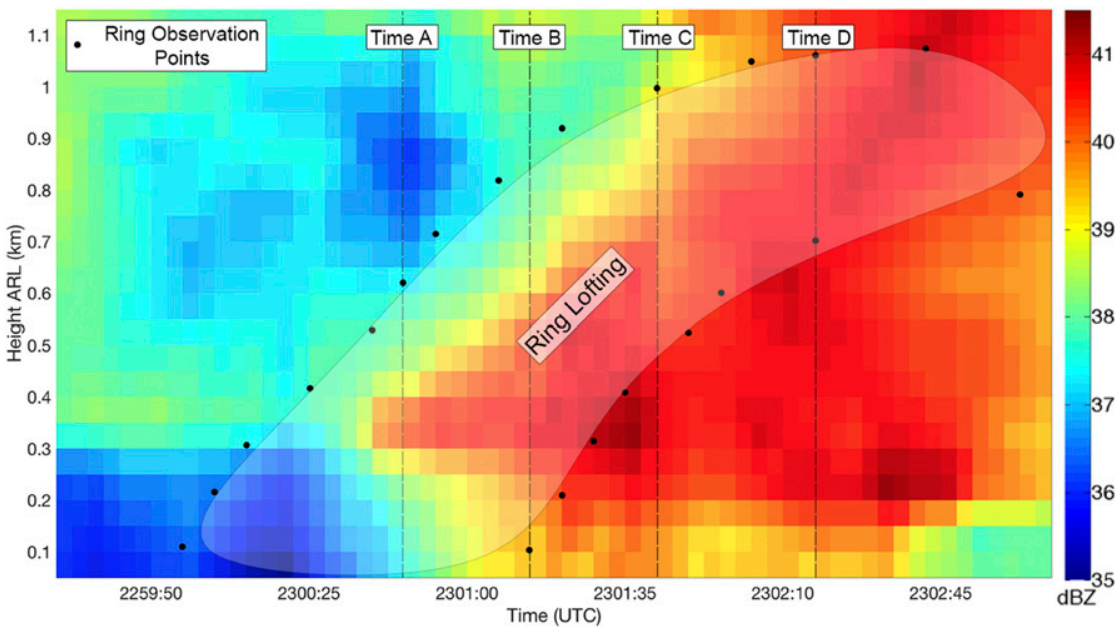

FIG. 7. A time-height plot (where height is ARL) showing the median reflectivity factor in the WEH (background color, in $\mathrm{dBZ}$ ). The upper row of dots represents the time at which the ring appears at a particular elevation, and the lower row of dots represents the time at which the ring disappears from a particular elevation. Times A-D are plotted as vertical lines for reference. These data are oversampled by a factor of 2 and smoothed with a moving-window average filter.

center point, dealiased radial velocity $v_{r}$ was overlaid on radar reflectivity, and the center was selected to be the intersection of the zero-isodop with the center of the WEC, as determined by a minimum in reflectivity. The center points were then overlaid on the PPIs to ensure that the location of the center points was correct.

An increase in reflectivity with height and time coincides with increased vortex tilt for the analyzed times (Fig. 8). Before the debris is lofted, the WEC tilt is no more than $10^{\circ}$ between 0.6 and $2 \mathrm{~km}$ ARL. Approximately $1 \mathrm{~min}$ after the median reflectivity factor in the WEH increases, the tilt of the WEC increases to over $30^{\circ}$. The increase in tilt manifests itself as an alteration to the track of the WEC at $\sim 2 \mathrm{~km}$ ARL (Figs. 9, 10). Based on the beam height at $3^{\circ}$ and $10^{\circ}$ in elevation, the tornado had an approximately linear track with small fluctuations, while the low-level mesocyclone exhibited much larger deviations. These track changes at approximately $2 \mathrm{~km}$ ARL represent a distinctly different behavior than that found in analysis of the 2013 Moore, Oklahoma, tornado (Kurdzo et al. 2015), where low-level scans $(\sim 500 \mathrm{~m}$ ARL) showed large track fluctuations. An animated scatterplot of the position of the tornado and the

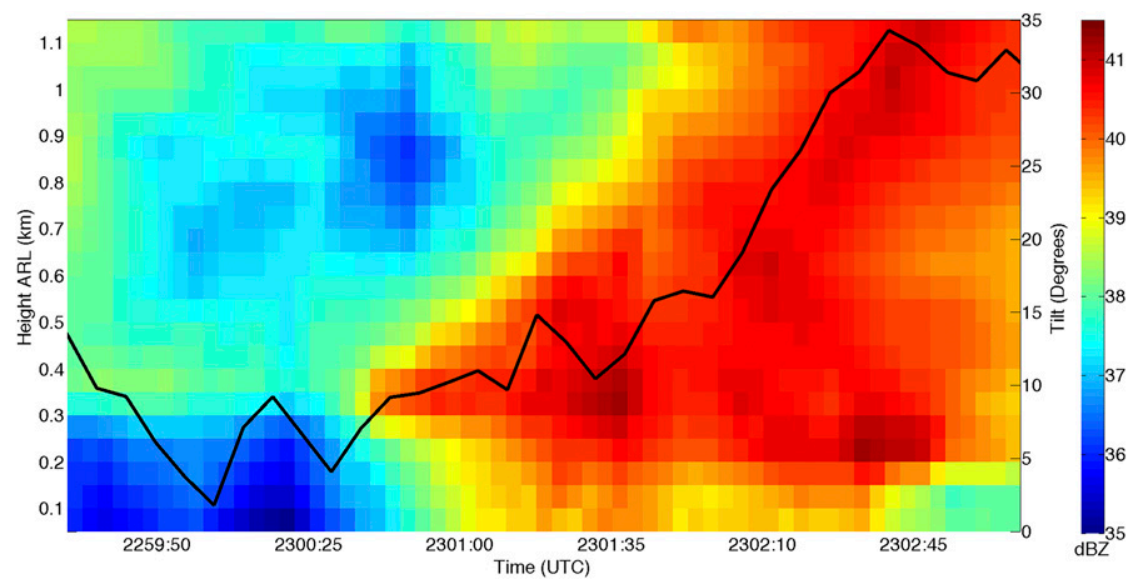

FIG. 8. A time-height plot (where height is ARL) showing the median reflectivity factor in the WEH (in $\mathrm{dBZ}$ ) and $3^{\circ}-10^{\circ}$ tilt angle (solid black line). Increased tilt lags behind debris lofting by approximately $45-60 \mathrm{~s}$. 


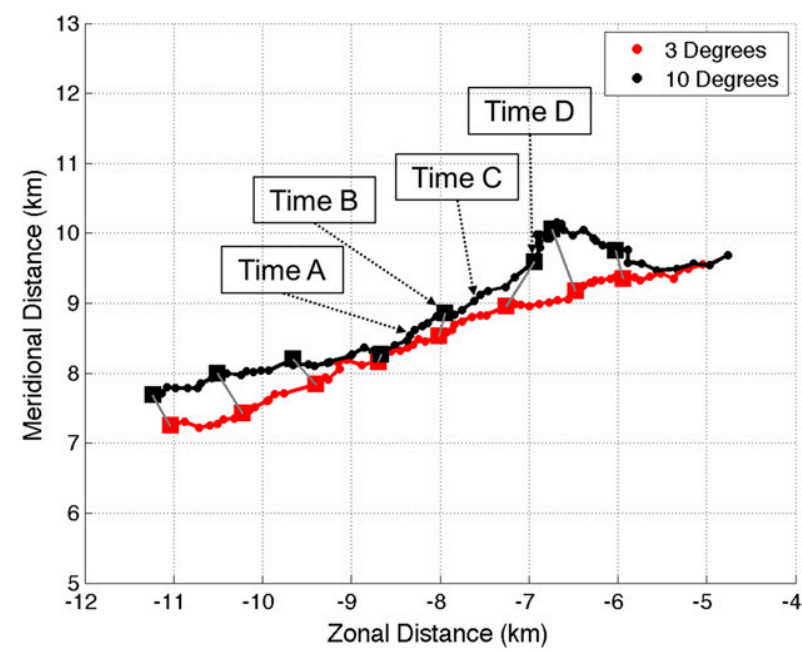

FIG. 9. A comparison of the track of the WEC at $3^{\circ}$ and $10^{\circ}$ between 2257:23 and 2305:06 UTC. Note that the direction of the track at $3^{\circ}$ is nearly constant, while the $10^{\circ}$ track contains more fluctuations, creating WEC tilt. Square points are spaced 1 min apart. Gray lines connect simultaneous square points, showing tilt direction. Zonal and meridional distances refer to distance from the AIR to the WEC center.

mesocyclone (similar to that shown in Fig. 9) is shown in Fig. S2 in the online supplemental material.

\section{2) TRACK CHANGES AND ASYMMETRIC REFLECTIVITY DISTRIBUTION}

To attempt to explain why the vortex became more tilted over time, the track of the WEC and the surrounding reflectivity field were analyzed at multiple heights. The comparison between different elevations is facilitated by the simultaneous RHIs of the AIR, such that no advection correction needs to be applied prior to analysis. Beginning around 2302:16 UTC, there is a clear northward shift in the track of the mesocyclone, as the mesocyclone (determined by $10^{\circ}$ elevation data) accelerates north and east, ahead of the WEC position at the tornado level. This northward turn lasts for about $1 \mathrm{~min}$ before the mesocyclone track turns to the southeast at around 2303:37 UTC. While we do not wish to posit a definitive causation between mesocyclone track shifts and reflectivity distribution around the WEC, asymmetric reflectivity distribution (ARD) around the mesocyclone ( $\sim 2 \mathrm{~km}$ ARL) is noted at the same time as the northward turn in the vortex track, with higher reflectivity on the north-northwest side of the mesocyclone (Fig. 10). As the mesocyclone slows and turns to the southeast, the reflectivity maximum on the northnorthwest side of the mesocyclone disappears, likely due to precipitation fallout. Simultaneous to the precipitation fallout, the mesocyclone remains nearly stationary for about $30 \mathrm{~s}$. Afterward, the vortex signature accelerates and moves east-southeast (between 2303:17 and 2304:59 UTC). A similar pattern was observed in Kurdzo et al. (2015), where the WEC took a sharp northward turn, slowed down, and then sped up while returning to an east-southeasterly track. However, the track changes in the Tipton tornado occur at higher elevations than those in the 2013 Moore tornado. Overall, asymmetric reflectivity distribution seems to be correlated with changes in the WEC track (Fig. 10). Asymmetric reflectivity distribution to the north and northwest sides of the WEC seems to correlate with the left (northward) turn, and asymmetric reflectivity distribution to the southeast side of the WEC precedes an eastsoutheasterly track. The track changes exhibited could be due to a downward transport of angular momentum from higher elevations toward the surface or due to a surge in the rear-flank gust front (RFGF). Further discussion of this theory will follow later in this section.

A subjective analysis of a three-dimensional representation of the storm (Fig. S1) reveals evidence of precipitation fallout, as a region of higher reflectivity on the northwest side of the storm descends between 2301 and 2303 UTC, with most rapid descent between 2302 and 2303 UTC. This volumetric representation of the storm shows the track of the WEC based on $3^{\circ}$ and $10^{\circ}$ elevation angle data, showing WEC tilt with time. The sudden decrease in reflectivity to the northwest side of the tornado between 2302:56 and 2303:37 UTC (Fig. 10) appears to be related to the aforementioned precipitation fallout. The precipitation fallout appears somewhat similar to a DRC, observed in Fig. S1. Byko et al. (2009) noted that in so-called Type III DRCs, lowlevel intensification of rotation could lead to a DRC via a downward pressure gradient force, similar to a mechanism believed to strengthen RFDs and occlusion downdrafts (Klemp and Rotunno 1983; Markowski 2002). Because a notable increase in tornado strength in the lowest $400 \mathrm{~m}$ is observed between 2302:16 and 2302: 45 UTC (discussed later in this study), the downwarddirected pressure gradient force could be a cause of the downward acceleration of the precipitation fallout and the sudden decrease in reflectivity approximately $2 \mathrm{~km}$ ARL. However, it is also possible that the observed DRC could be most similar to a Type I DRC (Byko et al. 2009), where midlevel flow stagnation causes water loading, leading to descent. This theory would be supported by the observed reflectivity maximum on the north-northwest side of the tornado at approximately $2 \mathrm{~km}$ AGL before the DRC descent (Fig. 10). It is also possible that a combination of these factors played a role in the DRC evolution, such that water loading and a downward-directed pressure gradient force caused the DRC. 

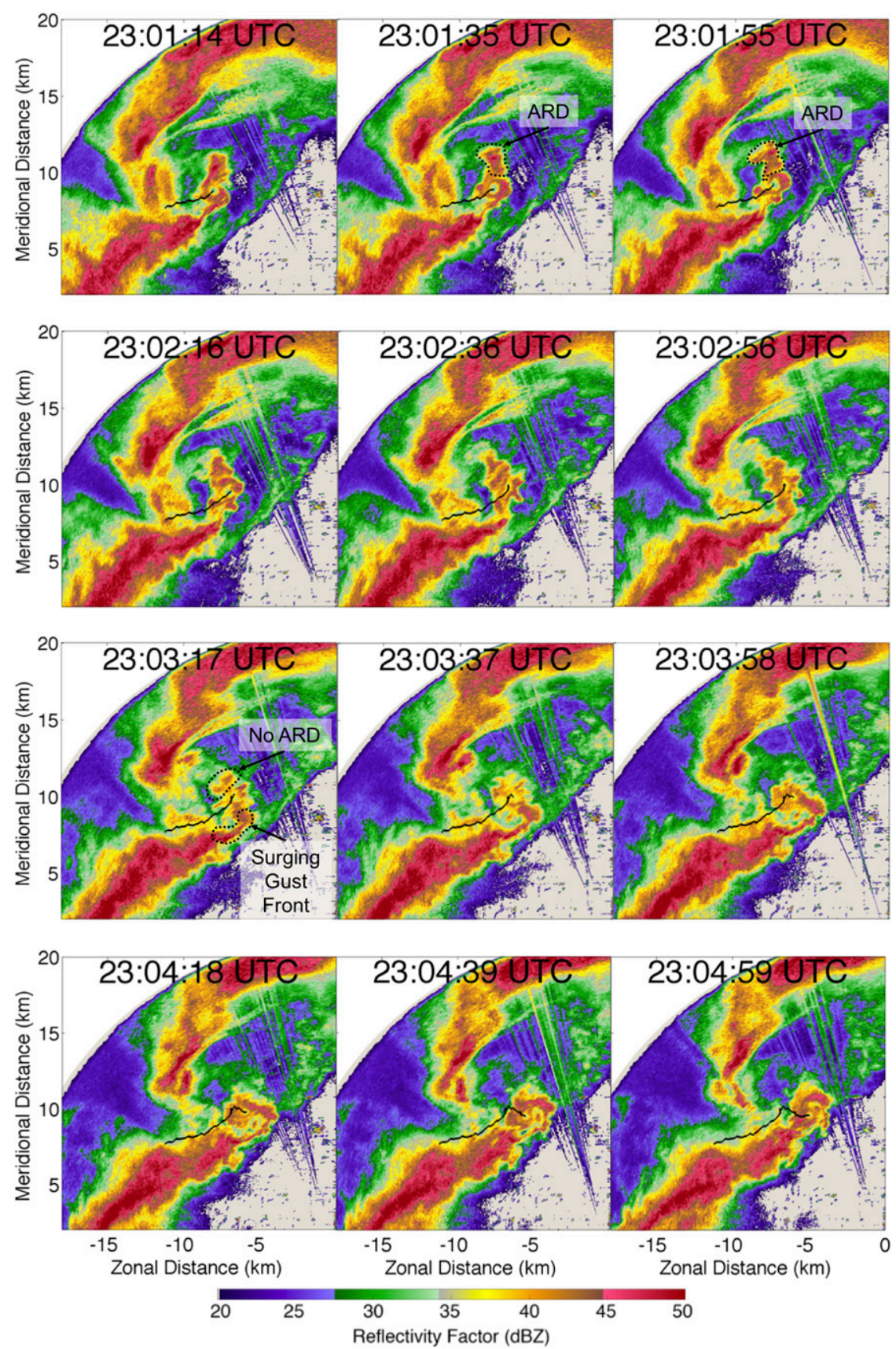

FIG. 10. PPI plots of reflectivity factor at $10^{\circ}$ in elevation. The black line overlaid shows the track of the WEC center. The appearance and disappearance of the ARD is noted, as well as the surging gust front.

Additionally, a bulge in the RFGF manifests in the reflectivity field to the southeast of the WEH (Fig. 10 at 2302:56 UTC). This bulge, which occurs immediately following the precipitation fallout/DRC, extends to the east of the WEH over several scans. By 2303:58 UTC, the reflectivity bulge extends nearly $2 \mathrm{~km}$ to the east of the WEH. While the RFGF has a nearly northsouth alignment before 2302:56 UTC, the RFGF takes on a "V" shape by 2303:58 UTC. After 2303:58 UTC, the WEH "catches up" to this leading edge via a sudden track change (significant acceleration and a track shift to the southeast). By 2304:59 UTC, the RFGF is back into near-alignment with the mesocyclone, similar to 2301:14 to 2302:36 UTC in Fig. 10. Thus, it is believed that the DRC may be the cause of the RFGF surge. 


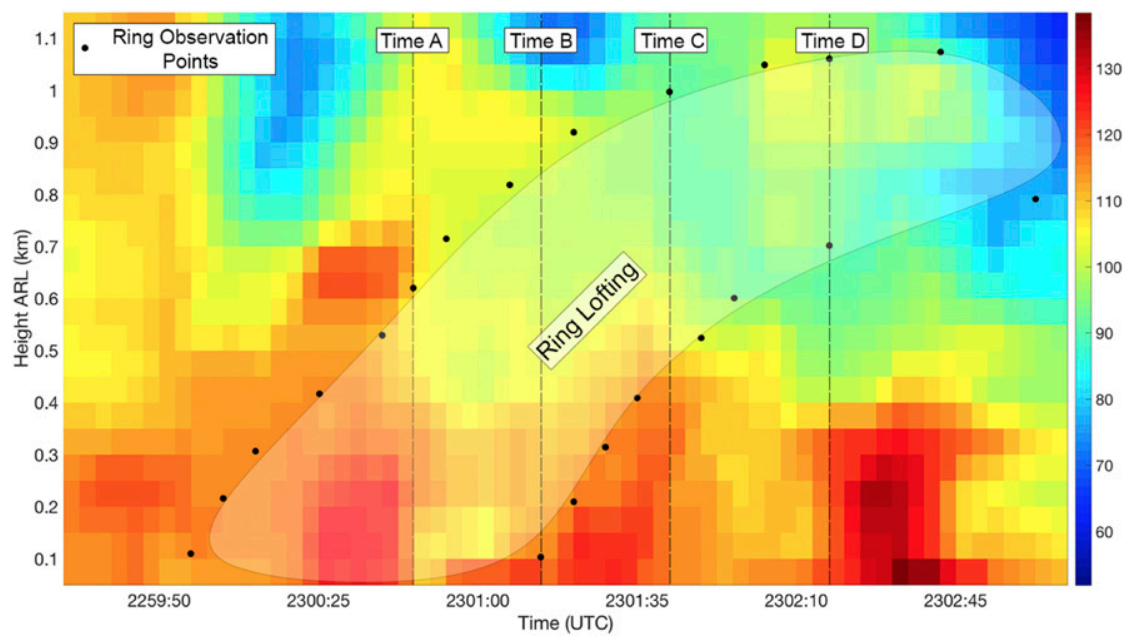

FIG. 11. A time-height plot (where height is ARL) showing the strength of the velocity couplet inside the tornado (in $\mathrm{m} \mathrm{s}^{-1}$ ). Ring observation points show the appearance of a lofted ring of higher reflectivity (top of "ring lofting") and the disappearance of a lofted ring (bottom of "ring lofting"). Times A-D are plotted for reference.

\section{3) Periodicity of tornado Strength}

To assess potential changes in tornado strength over time, $\Delta V$ was calculated from the dealiased velocity data. This calculation was achieved by comparing the maximum velocity difference between adjacent gates along the zero-isodop of the velocity couplet, and it should give an estimate of tornado strength. From these results, there is an oscillatory component of the strength of the velocity couplet in the lowest $300 \mathrm{~m}$, with $\Delta V$ maxima spaced approximately $1 \mathrm{~min}$ apart (Fig. 11). This periodicity is consistent with a result found in Wurman et al. (2013), where a distinct periodicity in tornado intensity was found at 66 and $108 \mathrm{~s}$. It is hypothesized in Wurman et al. (2013) that this is the result of longer-wavelength, upstream-propagating Rossby waves, due primarily to the fact that the period of the oscillations is significantly longer than the advective time scale of the tornado. French et al. (2014) also found a periodicity in vortex couplet strength, although these findings were at approximately $2 \mathrm{~km}$ AGL, with a longer period ( $3 \mathrm{~min}$ ) than the periodicity found in this study. Because the intensity oscillations in the Tipton tornado are of approximately the same period as the strongest periodicity found in Wurman et al. (2013), and because the period of the oscillations $(60 \mathrm{~s})$ is significantly longer than the approximate advective time scale $(\sim 20 \mathrm{~s})$, it is believed that the cause of the periodicity in the Tipton tornado and the tornado in Wurman et al. (2013) may be similar.

The first maximum in couplet strength appears at approximately 2300:30 UTC, and a nearly uniform and instantaneous increase in $\Delta V$ in the lowest $250 \mathrm{~m}$ ARL is observed. Preceding the final $\Delta V$ maxima in Fig. 11 at 2302:30 UTC, another increase in couplet strength that is instantaneous in height in the lowest $300 \mathrm{~m}$, similar to that observed in Houser et al. (2015), is observed. However, a different pattern exists in the $\Delta V$ increase in the couplet maxima at approximately 2301:30 UTC: the velocity first increases at the lowest elevation scans, followed by the higher heights within the tornado. This "bottom up" couplet strengthening has previously been observed by French et al. (2013) during tornadogenesis. Unlike the study by French et al. (2013), however, bottom-up couplet strengthening is observed during the mature stage of the Tipton tornado, rather than during tornadogenesis. This could be due to upward advection of vorticity, which would be in agreement with the observations of enhanced inflow and subsequent low-level convergence (Fig. 12). However, this bottom-up couplet intensification could be an artifact of debris bias in radial (relative to the radar) velocity estimation, although the lack of change in median reflectivity factor in the tornadic vortex (Fig. 7) could suggest that debris characteristics and associated velocity bias did not change.

\section{Discussion}

The results derived from the AIR-based GBVTD indicate that there is a region of radial inflow toward the vortex center in the lowest $400 \mathrm{~m}$ (Fig. 12). This region of inflow intensifies at times $\mathrm{C}$ and $\mathrm{D}$, with a region of radial convergence present. The resulting inflow at low 

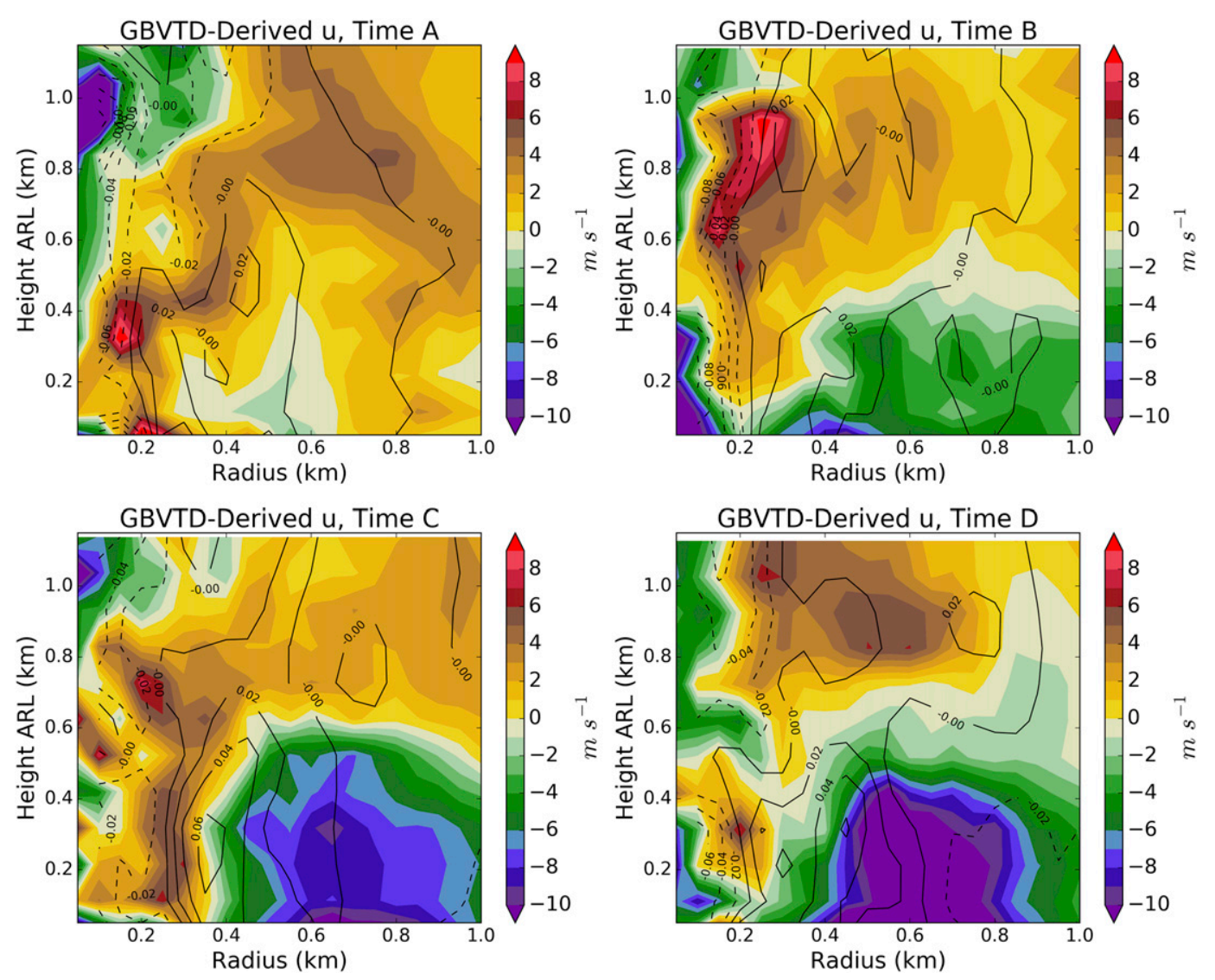

FIG. 12. Axisymmetric plots at times A-D (2300:47, 2301:14, 2301:42, and 2302:16 UTC) showing GBVTDderived $u$ in $\mathrm{m} \mathrm{s}^{-1}$ at four times (underlay) and radial convergence (contours) in $\mathrm{s}^{-1}$. Positive convergence values (solid contours) correspond to convergence, and negative convergence values (dashed contours) correspond to divergence. A Gaussian smoothing filter has been applied to radial convergence. Note the convergence in the lowest $600 \mathrm{~m}$ at $300-600 \mathrm{~m}$ in radius in the bottom two panels. The lowest analyzed height is approximately $60 \mathrm{~m}$.

levels at some of the analyzed times is consistent with previous tornado simulations and observations (e.g., Lewellen et al. 2000; Tanamachi et al. 2007; Bodine et al. 2016b), although unlike many previous studies (Kosiba and Wurman 2010; Nolan 2013), the inflow does not appear to extend inward to the radius of maximum winds (RMW). This discrepancy could be due to the inflow extending into the RMW at a lower altitude than sampled, or it could be due to debris centrifuging bias. The radial convergence/divergence contours plotted on each panel in Fig. 12 are calculated directly from the $u$ underlay.

This radial inflow pattern has two possible implications for the Tipton tornado. First, the enhanced surface convergence corresponds to upward motion at this radius. This upward motion coincides both spatially and temporally with the observed vertical deepening and eventual upward advection of the debris ring. Therefore, the kinematic changes of the debris ring could be due to the enhanced surface convergence; however, this is purely speculative and could be coincidental. Another plausible hypothesis could be that the tornado passed over a debris source, increasing the amount of debris lofted. The timing of the debris lofting coincides with the tornado passing over a wooded area along a riverbank. However, because the damage survey did not cover this portion of the tornado path, it is unclear whether these trees could have been lofted by the tornado.

Second, the enhanced inflow is collocated with an inward advection of lower-angular momentum air toward the vortex center (Fig. 13). For example, between times $\mathrm{B}$ and $\mathrm{D}$, the $15 \mathrm{~m} \mathrm{~s}^{-1}$ isotach of tangential wind moves from approximately 700 to $500 \mathrm{~m}$ in radius in the lowest few hundred meters. Additionally, at time D, lowerangular momentum air has advected underneath the radial maximum in angular momentum in the lowest $100 \mathrm{~m}$ ARL. This could result from lower-angular momentum being transported downward by the DRC and could explain the vortex couplet weakening between 2302:29 and 2303:10 UTC (Fig. 11). 

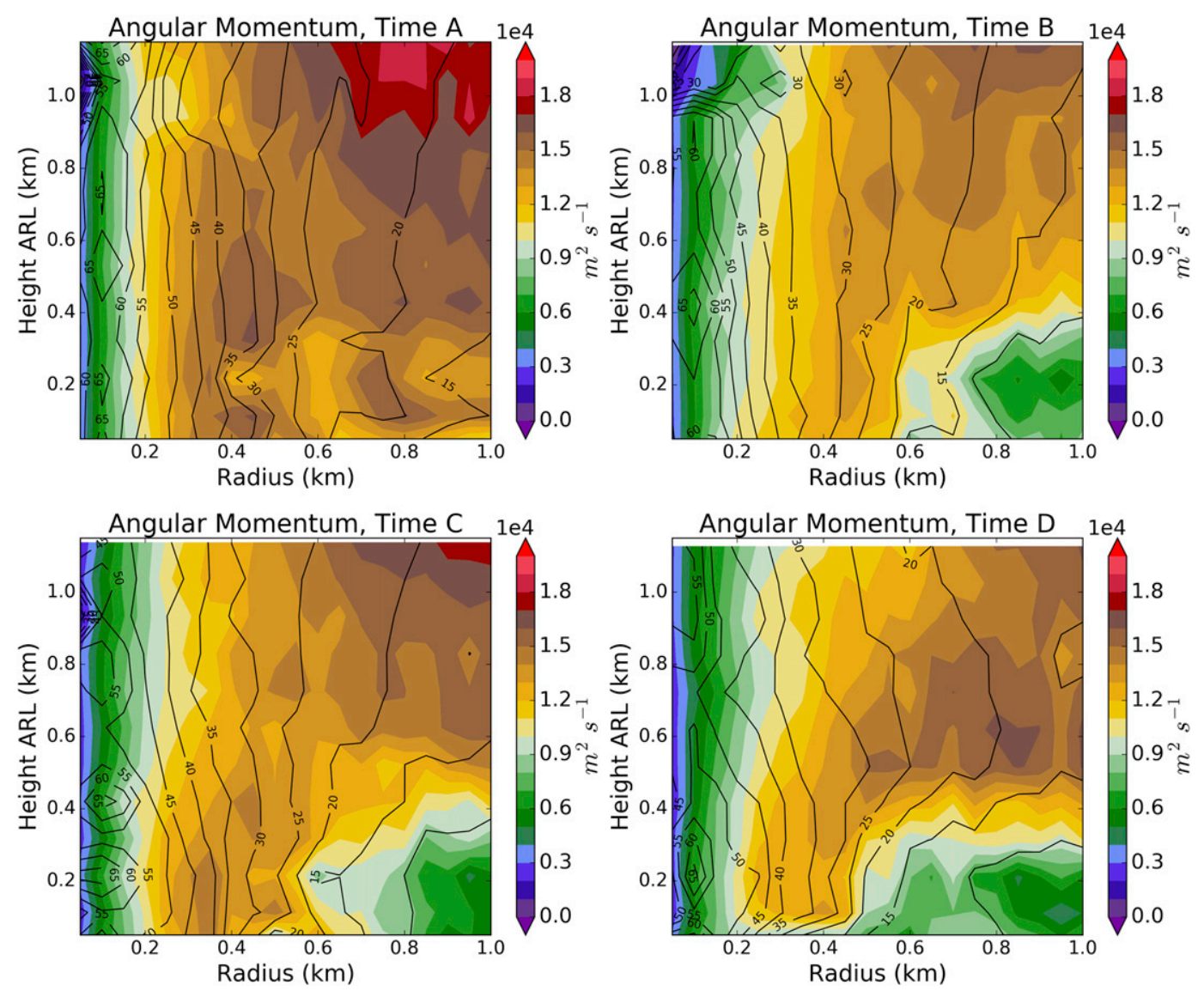

FIG. 13. Axisymmetric plots at times A-D (2300:47, 2301:14, 2301:42, and 2302:16 UTC) for angular momentum (in $\mathrm{m}^{2} \mathrm{~s}^{-1}$, underlay). Tangential velocity $\left(v\right.$, in $\left.\mathrm{m} \mathrm{s}^{-1}\right)$ is plotted as a contour.

During the analyzed portion of the mature stage of the tornado, WEC tilt angle increases drastically. This increase is believed to be a result of rearward stormrelative motion of the low-level mesocyclone. The debris lofting is correlated with an increase in WEC tilt angle (Fig. 8), although the causation of these two events is not immediately obvious. While it is not clear how the debris lofting process is related to changes in tilt, the change in tilt angle appears to be related to other reflectivity motion via a possible DRC. Asymmetric reflectivity distribution aloft (approximately $2 \mathrm{~km}$ ARL) is observed at the same zonal and meridional coordinates as the DRC, directly prior to downward acceleration and cyclonic advection of the DRC.

The observation of DRCs coinciding with immediate couplet weakening in the Tipton tornado differs from several previous observations, in which DRCs and their subsequent rear-flank gust front surges have generally been shown to lead to an immediate increase in tornado intensity (Dowell and Bluestein 2002; Lee et al. 2012). The role of DRCs with regard to tornadogenesis has been assessed by previous studies; DRCs are primarily believed to be associated (although not exclusively) with tornadogenesis, evolution of the hook echo, downbursts and subsequent damaging surface-level winds, and/or a rapid intensification of low-level circulation via flow modulation (Van Den Broeke et al. 2008; Markowski et al. 2012; Kosiba et al. 2013; Kuster et al. 2016).

However, previous studies have shown that tornado weakening can occur via an "occlusion" of the tornado (Adlerman et al. 1999; Marquis et al. 2012), or temporary weakening can occur in the event of a failed occlusion (Kurdzo et al. 2015). Weakening via an occlusion is believed to be caused by either interruption of the inflow and ingestion of vorticity or by introduction of cold air into the inflow, as RFDs have been shown to be associated with cold air from aloft due to evaporative cooling, hail melting, or precipitation loading (Markowski 2002). Paradoxically, previous studies have shown that cooler air (cold pools) around the inflow can induce baroclinic vorticity generation when negative buoyancy is not terribly strong, but strong cold pools can 
significantly inhibit tornadogenesis (Markowski et al. 2002; Grzych et al. 2007). However, because there were no surface thermodynamic data recorded for the Tipton tornado, the thermodynamic properties of the DRC and rear-flank downdraft (RFD) are unknown. Thus, it is unclear whether or not an occlusion, a failed occlusion, an attendant cold pool, or some other phenomenon was the cause of the weakening observed in the Tipton tornado. Thermodynamic retrieval using a data assimilation technique (such as EnKF) could provide additional insight for this case.

\section{Conclusions}

In this study, a tornado case from southwestern Oklahoma on 16 May 2015 is analyzed. This EF-3 tornado impacted the towns of Elmer, Tipton, and Snyder, Oklahoma, and persisted for over an hour. The AIR collected data on this storm for $32 \mathrm{~min}$, while the analysis herein centers on a $\sim 5$ min subsection of this dataset during the mature stage of this tornado. The storm is studied via time-height plots of reflectivity and velocity, a tilt analysis of the tornadic vortex, a comparison between AIR and WSR-88D (KFDR) data, and a GBVTD-based analysis. Using AIR data, a reflectivity maximum in the shape of a toroid is observed during the mature stage of the tornado, evolving on the order of a few tens of seconds. This toroid/ring, which is located interior to the outer $\mathrm{WEH}$, expands in radius around the tornado while simultaneously deepening to approximately $1 \mathrm{~km}$ ARL. Using KFDR and AIR data, a TDS is observed via collocation of lowered $\rho_{\text {hv }}$ with higher $Z_{H}$ near the vortex center. Similar ring lofting has been observed in previous studies, with debris ring lofting and expansion occurring on similar spatial and temporal scales.

Additionally, results from the GBVTD analysis show radial inflow near the surface several hundred meters from the vortex center, resulting in strong radial convergence at $300-600 \mathrm{~m}$ in radius. Similarly, an outer region of lower-angular momentum in the lowest $300 \mathrm{~m}$ ARL impinges upon the radial maximum in angular momentum (Fig. 13). The observation of surface convergence $\sim 400 \mathrm{~m}$ away from the axis of rotation, combined with increased surface divergence along the axis of rotation, could be indicative of a two-celled vortex.

Approximately $60 \mathrm{~s}$ after debris lofting begins, tilt between the tornado and the low-level mesocyclone begins to increase. This is reflected in mesocyclone track changes at about $2 \mathrm{~km}$ ARL, while the track of the WEC in the lowest $1 \mathrm{~km}$ is largely unaltered. The tilt of the WEC greatly increases and returns to its original $\left(<10^{\circ}\right)$ orientation over approximately $3 \mathrm{~min}$. This tilt increase is contrasted with results in Kurdzo et al. (2015), where track changes were observed more readily at lower levels than upper levels. The track of the vortex at the mesocyclone level (based on $10^{\circ}$ elevation angle data) in the Tipton tornado takes a sharp northward turn, leading to a northward tilt of the vortex with height. The debris lofting at low levels and vortex tilting coincides with an asymmetric reflectivity distribution approximately $2 \mathrm{~km}$ ARL, which could be associated with a DRC. Coincident with the decrease in reflectivity at the mesocyclone level, a DRC descends and wraps cyclonically around the west side of the tornado (Fig. S1).

Throughout the analyzed portion of the mature stage of the tornado, a periodicity in tornado strength is noted on the order of $1 \mathrm{~min}$. This periodicity is compared with results found in Wurman et al. (2013), where a similar periodicity in tornado intensity is observed. Two intensifications occur simultaneously over the lowest $400 \mathrm{~m}$, and one intensification occurs in a bottom-up manner, in which vortex couplet strength increased near the surface first and advected upward over $30 \mathrm{~s}$. In recent years, studies using mobile radars have found a bottomup intensification during tornadogenesis (e.g., French et al. 2013), yet few studies have addressed vertical development of changes in tornado strength during the mature phase. The transmitted fan beam and simultaneous receive beams of the AIR aid in this type of analysis, as no horizontal or vertical advection between elevations needs to be accounted for.

In conclusion, we have noted the following in our analysis:

- rapid ascent of debris and formation of a ring interior to the outer WEH on the order of 30-60 s;

- rapid intensification of surface convergence, aligning with a region of enhanced debris lofting;

- collocation between enhanced reflectivity and lowered $\rho_{\mathrm{hv}}$, indicating debris presence;

- a DRC that "wraps around" the tornado over time, similar to that seen in a failed occlusion, is observed immediately following an asymmetric reflectivity distribution around the vortex, and was simultaneous with changes in vortex tilt, owing to notable track changes in low-level mesocyclone position at $2 \mathrm{~km}$ but a constant track at $600 \mathrm{~m}$;

- strong periodicity in vortex couplet strength, with a period ( $\sim 60 \mathrm{~s})$ significantly longer than the advective time scale of the tornado; and

- multiple modes of vertical evolution (bottom-up intensification as well as simultaneous intensification over the lowest $400 \mathrm{~m}$ ) during the mature stage of the tornado.

This analysis was greatly aided by the coincidental proximity of KFDR. Without these polarimetric data, 
many of the assertions regarding debris presence would not be possible. It is our hope that an improved, polarimetric version of the AIR currently under development (PAIR; Salazar-Cerreño et al. 2017) will allow for hightemporal-resolution polarimetric analysis on any tornadic storm observed by the PAIR, instead of just tornadoes that serendipitously occur near a NEXRAD site.

Acknowledgments. The authors thank Jon Christian and Javier Lujan for driving and operating the radar on 16 May 2015, the ARRC technical staff for their assistance in maintaining and troubleshooting the AIR, and Feng Nai for his work on creating AIR processing scripts. Additionally, comments from two anonymous reviewers greatly helped improve the content and style of this paper. This project was supported by NOAA/Oceanic and Atmospheric Research under NOAA-University of Oklahoma Cooperative Agreement NA11OAR4320072, U.S. Department of Commerce. The authors would also like acknowledge support from the National Science Foundation under Grant AGS-1303685.

\section{REFERENCES}

Adachi, T., K. Kusunoki, S. Yoshida, K.-I. Arai, and T. Ushio, 2016: High-speed volumetric observation of a wet microburst using $\mathrm{X}$-band phased array weather radar in Japan. Mon. Wea. Rev., 144, 3749-3765, https://doi.org/10.1175/MWR-D-16-0125.1.

Adlerman, E. J., K. K. Droegemeier, and R. Davies-Jones, 1999: A numerical simulation of cyclic mesocyclogenesis. J. Atmos. Sci., 56, 2045-2069, https://doi.org/10.1175/1520-0469(1999)056<2045: ANSOCM $>2.0 . \mathrm{CO} ; 2$.

Attia, E. H., and B. D. Steinberg, 1989: Self-cohering large antenna arrays using the spatial correlation properties of radar clutter. IEEE Trans. Antennas Propag., 37, 30-38, https://doi.org/ 10.1109/8.192160.

Beck, J. R., J. L. Schroeder, and J. M. Wurman, 2006: Highresolution dual-Doppler analysis of the 29 May 2001 Kress, Texas, cyclic supercell. Mon. Wea. Rev., 134, 3125-3148, https://doi.org/10.1175/MWR3246.1.

Bluestein, H. B., W.-C. Lee, M. Bell, C. C. Weiss, and A. L. Pazmany, 2003: Mobile Doppler radar observations of a tornado in a supercell near Bassett, Nebraska, on 5 June 1999. Part II: Tornado-vortex structure. Mon. Wea. Rev., 131, 2968-2984, https://doi.org/10.1175/1520-0493(2003)131<2968: MDROOA $>2.0 . \mathrm{CO} ; 2$.

—, M. M. French, R. L. Tanamachi, S. Frasier, K. Hardwick, F. Junyent, and A. L. Pazmany, 2007a: Close-range observations of tornadoes in supercells made with a dual-polarization, X-band, mobile Doppler radar. Mon. Wea. Rev., 135, 15221543, https://doi.org/10.1175/MWR3349.1.

_ C. C. Weiss, M. M. French, E. M. Holthaus, R. L. Tanamachi, S. Frasier, and A. L. Pazmany, 2007b: The structure of tornadoes near Attica, Kansas, on 12 May 2004: Highresolution, mobile, Doppler radar observations. Mon. Wea. Rev., 135, 475-506, https://doi.org/10.1175/MWR3295.1.

—, M. M. French, I. PopStefanija, R. T. Bluth, and J. B. Knorr, 2010: A mobile, phased-array Doppler radar for the study of severe convective storms: The MWR-05XP. Bull. Amer. Meteor. Soc., 91, 579-600, https://doi.org/10.1175/2009BAMS2914.1.

_, and Coauthors, 2014: Radar in atmospheric sciences and related research: Current systems, emerging technology, and future needs. Bull. Amer. Meteor. Soc., 95, 1850-1861, https:// doi.org/10.1175/BAMS-D-13-00079.1.

Bodine, D. J., M. R. Kumjian, R. D. Palmer, P. L. Heinselman, and A. V. Ryzhkov, 2013: Tornado damage estimation using polarimetric radar. Wea. Forecasting, 28, 139-158, https://doi.org/ 10.1175/WAF-D-11-00158.1.

, R. D. Palmer, and G. Zhang, 2014: Dual-wavelength polarimetric radar analyses of tornadic debris signatures. J. Appl. Meteor. Climatol., 53, 242-261, https://doi.org/10.1175/JAMC-D-13-0189.1.

—, T. Maruyama, R. D. Palmer, C. J. Fulton, H. B. Bluestein, and D. C. Lewellen, 2016a: Sensitivity of tornado dynamics to soil debris loading. J. Atmos. Sci., 73, 2783-2801, https://doi.org/ 10.1175/JAS-D-15-0188.1.

, R. D. Palmer, T. Maruyama, C. J. Fulton, Y. Zhu, and B. L. Cheong, 2016b: Simulated frequency dependence of radar observations of tornadoes. J. Atmos. Oceanic Technol., 33, 1825-1842, https://doi.org/10.1175/JTECH-D-15-0120.1.

Byko, Z., P. Markowski, Y. Richardson, J. Wurman, and E. Adlerman, 2009: Descending reflectivity cores in supercell thunderstorms observed by mobile radars and in a high-resolution numerical simulation. Wea. Forecasting, 24, 155-186, https://doi.org/10.1175/ 2008WAF2222116.1.

Dolan, B., and S. A. Rutledge, 2009: A theory-based hydrometeor identification algorithm for X-band polarimetric radars. J. Atmos. Oceanic Technol., 26, 2071-2088, https://doi.org/ 10.1175/2009JTECHA1208.1.

Doviak, R. J., and D. S. Zrnić, 2006: Doppler Radar \& Weather Observations. Dover Publications, Inc., 562 pp.

Dowell, D. C., and H. B. Bluestein, 2002: The 8 June 1995 McLean, Texas, storm. Part II: Cyclic tornado formation, maintenance, and dissipation. Mon. Wea. Rev., 130, 2649-2670, https://doi.org/ 10.1175/1520-0493(2002)130<2649:TJMTSP>2.0.CO;2.

—, C. R. Alexander, J. M. Wurman, and L. J. Wicker, 2005: Centrifuging of hydrometeors and debris in tornadoes: Radarreflectivity patterns and wind-measurement errors. Mon. Wea. Rev., 133, 1501-1524, https://doi.org/10.1175/MWR2934.1.

French, M. M., H. B. Bluestein, I. PopStefanija, C. A. Baldi, and R. T. Bluth, 2013: Reexamining the vertical development of tornadic vortex signatures in supercells. Mon. Wea. Rev., 141, 4576-4601, https://doi.org/10.1175/MWR-D-12-00315.1.

,,,---- , and -2014 : Mobile, phased-array, Doppler radar observations of tornadoes at X band. Mon. Wea. Rev., 142, 1010-1036, https://doi.org/10.1175/MWR-D-13-00101.1.

Fujita, T. T., 1981: Tornadoes and downbursts in the context of generalized planetary scales. J. Atmos. Sci., 38, 1511-1534, https://doi.org/ 10.1175/1520-0469(1981)038<1511:TADITC > 2.0.CO;2.

Griffin, C. B., D. J. Bodine, and R. D. Palmer, 2017: Kinematic and polarimetric radar observations of the 10 May 2010, Moore-Choctaw, Oklahoma, tornadic debris signature. Mon. Wea. Rev., 145, 2723-2741, https://doi.org/10.1175/ MWR-D-16-0344.1.

Grzych, M. L., B. D. Lee, and C. A. Finley, 2007: Thermodynamic analysis of supercell rear-flank downdrafts from Project ANSWERS. Mon. Wea. Rev., 135, 240-246, https://doi.org/ 10.1175/MWR3288.1.

Heinselman, P. L., and S. M. Torres, 2011: High-temporal-resolution capabilities of the National Weather Radar Testbed PhasedArray Radar. J. Appl. Meteor. Climatol., 50, 579-593, https:// doi.org/10.1175/2010JAMC2588.1. 
Houser, J. L., H. B. Bluestein, and J. C. Snyder, 2015: Rapid-scan, polarimetric, Doppler radar observations of tornadogenesis and tornado dissipation in a tornadic supercell: The "El Reno, Oklahoma" storm of 24 May 2011. Mon. Wea. Rev., 143, 26852710, https://doi.org/10.1175/MWR-D-14-00253.1.

,-- , and — 2016: A finescale radar examination of the tornadic debris signature and weak-echo reflectivity band associated with a large, violent tornado. Mon. Wea. Rev., 144, 4101-4130, https://doi.org/10.1175/MWR-D-15-0408.1.

Isom, B., and Coauthors, 2013: The atmospheric imaging radar: Simultaneous volumetric observations using a phased array weather radar. J. Atmos. Oceanic Technol., 30, 655-675, https://doi.org/10.1175/JTECH-D-12-00063.1.

Jou, B. J.-D., W.-C. Lee, S.-P. Liu, and Y.-C. Kao, 2008: Generalized VTD retrieval of atmospheric vortex kinematic structure. Part I: Formulation and error analysis. Mon. Wea. Rev., 136, 995-1012, https://doi.org/10.1175/2007MWR2116.1.

Kashiwayanagi, T., K. Morotomi, O. Sato, and H. Sugawara, 2016: Rapid 3D scanning high resolution X-band weather radar with active phased array antenna. Tech. Conf. on Meteorological and Environmental Instruments and Methods of Observation, Madrid, Spain, WMO, P2(34), https://www.wmocimo.net/ eventpapers/session2/posters2/P2(34)_Kashiwayanagi_Rapid_3D_ Scanning.pdf

Klemp, J. B., and R. Rotunno, 1983: A study of the tornadic region within a supercell thunderstorm. J. Atmos. Sci., 40, 359-377, https:// doi.org/10.1175/1520-0469(1983)040<0359:ASOTTR > 2.0.CO;2.

Kosiba, K. A., and J. Wurman, 2010: The three-dimensional axisymmetric wind field structure of the Spencer, South Dakota, 1998 tornado. J. Atmos. Sci., 67, 3074-3083, https://doi.org/ 10.1175/2010JAS3416.1.

—, R. J. Trapp, and J. Wurman, 2008: An analysis of the axisymmetric three-dimensional low level wind field in a tornado using mobile radar observations. Geophys. Res. Lett., 35, L05805, https://doi.org/10.1029/2007GL031851.

__, J. Wurman, Y. Richardson, P. Markowski, P. Robinson, and J. Marquis, 2013: Genesis of the Goshen County, Wyoming, tornado on 5 June 2009 during VORTEX2. Mon. Wea. Rev., 141, 1157-1181, https://doi.org/10.1175/ MWR-D-12-00056.1.

Kumjian, M. R., and A. V. Ryzhkov, 2008: Polarimetric signatures in supercell thunderstorms. J. Appl. Meteor. Climatol., 47, 1940-1961, https://doi.org/10.1175/2007JAMC1874.1.

Kurdzo, J. M., B.-L. Cheong, R. D. Palmer, G. Zhang, and J. B. Meier, 2014: A pulse compression waveform for improvedsensitivity weather radar observations. J. Atmos. Oceanic Technol., 31, 2713-2731, https://doi.org/10.1175/JTECH-D13-00021.1.

—, D. J. Bodine, B. L. Cheong, and R. D. Palmer, 2015: Hightemporal resolution polarimetric X-band Doppler radar observations of the 20 May 2013 Moore, Oklahoma, tornado. Mon. Wea. Rev., 143, 2711-2735, https://doi.org/10.1175/ MWR-D-14-00357.1.

— , and Coauthors, 2017: Observations of severe local storms and tornadoes with the atmospheric imaging radar. Bull. Amer. Meteor. Soc., 98, 915-935, https://doi.org/10.1175/BAMS-D-15-00266.1.

Kuster, C. M., P. L. Heinselman, and T. J. Schuur, 2016: Rapid-update radar observations of downbursts occurring within an intense multicell thunderstorm on 14 June 2011. Wea. Forecasting, 31, 827-851, https://doi.org/10.1175/WAF-D-15-0081.1.

Lee, B. D., C. A. Finley, and C. D. Karstens, 2012: The Bowdle, South Dakota, cyclic tornadic supercell of 22 May 2010: Surface analysis of rear-flank downdraft evolution and multiple internal surges. Mon. Wea. Rev., 140, 3419-3441, https://doi.org/10.1175/ MWR-D-11-00351.1.

Lee, W.-C., and J. Wurman, 2005: Diagnosed three-dimensional axisymmetric structure of the Mulhall tornado on 3 May 1999. J. Atmos. Sci., 62, 2373-2393, https://doi.org/10.1175/JAS3489.1.

_ , F. D. Marks, and R. E. Carbone, 1994: Velocity track display_A technique to extract real-time tropical cyclone circulations using a single airborne Doppler radar. J. Atmos. Oceanic Technol., 11, 337-356, https://doi.org/10.1175/1520-0426(1994)011<0337: VTDTTE $>2.0 . \mathrm{CO} ; 2$.

— B. J.-D. Jou, P.-L. Chang, and S.-M. Deng, 1999: Tropical cyclone kinematic structure retrieved from single-Doppler radar observations. Part I: Interpretation of Doppler velocity patterns and the GBVTD technique. Mon. Wea. Rev., 127, 2419-2439, https://doi.org/10.1175/1520-0493(1999)127<2419: TCKSRF $>2.0 . \mathrm{CO} ; 2$.

Leslie, F. W., and J. T. Snow, 1980: Sullivan's two-celled vortex. AIAA J., 18, 1272-1274, https://doi.org/10.2514/3.7723.

Lewellen, D. C., W. S. Lewellen, and J. Xia, 2000: The influence of a local swirl ratio on tornado intensification near the surface. J. Atmos. Sci., 57, 527-544, https://doi.org/10.1175/1520-0469(2000)057<0527: TIOALS $>2.0 . \mathrm{CO} ; 2$.

_ B. Bong, and W. S. Lewellen, 2008: Effects of finescale debris on near-surface tornado dynamics. J. Atmos. Sci., 65, 32473262, https://doi.org/10.1175/2008JAS2686.1.

Liou, Y.-C., T.-C. Chen Wang, W.-C. Lee, and Y.-J. Chang, 2006: The retrieval of asymmetric tropical cyclone structures using Doppler radar simulations and observations with the extended GBVTD technique. Mon. Wea. Rev., 134, 1140-1160, https:// doi.org/10.1175/MWR3107.1.

Mahre, A., T.-Y. Yu, R. D. Palmer, and J. M. Kurdzo, 2017: Observations of a cold front at high spatiotemporal resolution using an X-band phased array imaging radar. Atmosphere, $\mathbf{8}$, 30, https://doi.org/10.3390/atmos8020030.

Markowski, P. M., 2002: Hook echoes and rear-flank downdrafts: A review. Mon. Wea. Rev., 130, 852-876, https://doi.org/10.1175/ 1520-0493(2002)130<0852:HEARFD > 2.0.CO;2.

— J. M. Straka, and E. N. Rasmussen, 2002: Direct surface thermodynamic observations within the rear-flank downdrafts of nontornadic and tornadic supercells. Mon. Wea. Rev., 130, 1692-1721, https://doi.org/10.1175/1520-0493(2002)130<1692: DSTOWT $>2.0 . \mathrm{CO} ; 2$.

_ - and Coauthors, 2012: The pretornadic phase of the Goshen County, Wyoming, supercell of 5 June 2009 intercepted by VORTEX2. Part II: Intensification of low-level rotation. Mon. Wea. Rev., 140, 2916-2938, https://doi.org/10.1175/MWR-D11-00337.1.

Marquis, J., Y. Richardson, P. Markowski, D. Dowell, and J. Wurman, 2012: Tornado maintenance investigated with high-resolution dual-Doppler and EnKF analysis. Mon. Wea. Rev., 140, 3-27, https://doi.org/10.1175/MWR-D-11-00025.1.

Nolan, D. S., 2013: On the use of Doppler radar-derived wind fields to diagnose the secondary circulations of tornadoes. J. Atmos. Sci., 70, 1160-1171, https://doi.org/10.1175/JAS-D-12-0200.1.

_ , and B. F. Farrell, 1999: The structure and dynamics of tornadolike vortices. J. Atmos. Sci., 56, 2908-2936, https://doi.org/ 10.1175/1520-0469(1999)056<2908:TSADOT >2.0.CO;2.

Palmer, R. D., and Coauthors, 2011: Observations of the 10 May 2010 tornado outbreak using OU-PRIME: Potential for new science with high-resolution polarimetric radar. Bull. Amer. Meteor. Soc., 92, 871-891, https://doi.org/10.1175/2011BAMS3125.1.

Pazmany, A. L., J. B. Mead, H. B. Bluestein, J. C. Snyder, and J. B. Houser, 2013: A mobile rapid-scanning X-band polarimetric 
(RaXPol) Doppler radar system. J. Atmos. Oceanic Technol., 30, 1398-1413, https://doi.org/10.1175/JTECH-D-12-00166.1.

Potvin, C. K., A. Shapiro, T.-Y. Yu, J. Gao, and M. Xue, 2009: Using a low-order model to detect and characterize tornadoes in multiple-Doppler radar data. Mon. Wea. Rev., 137, 1230 1249, https://doi.org/10.1175/2008MWR2446.1.

Ryzhkov, A. V., D. W. Burgess, D. S. Zrnić, T. Smith, and S. E. Giangrande, 2002: Polarimetric analysis of a 3 May 1999 tornado. Preprints, 21st Conf. on Severe Local Storms, San Antonio, TX, Amer. Meteor. Soc., 14.2, https://ams.confex.com/ams/ SLS_WAF_NWP/techprogram/paper_47348.htm.

— T. J. Schuur, D. W. Burgess, and D. S. Zrnić, 2005: Polarimetric tornado detection. J. Appl. Meteor., 44, 557-570, https://doi.org/10.1175/JAM2235.1.

Salazar-Cerreño, J. L., and Coauthors, 2017: Development of a mobile C-band polarimetric atmospheric imaging radar (PAIR). 97th AMS Annual Meeting, Seattle, WA, Amer. Meteor. Soc., 1B.1, https://ams.confex.com/ams/97Annual/ webprogram/Paper308655.html.

Schultz, C. J., and Coauthors, 2012: Dual-polarization tornadic debris signatures. Part I: Examples and utility in an operational setting. Electron. J. Operational Meteor., 13, 120-137.

Skolnik, M. I., 2001: Introduction to Radar Systems. McGraw-Hill Education, $784 \mathrm{pp}$.

__, 2008: Radar Handbook. McGraw-Hill Education, 1328 pp.

Snyder, J. C., and A. V. Ryzhkov, 2015: Automated detection of polarimetric tornadic debris signatures using a hydrometeor classification algorithm. J. Appl. Meteor. Climatol., 54, 18611870, https://doi.org/10.1175/JAMC-D-15-0138.1.

— H. B. Bluestein, D. T. Dawson II, and Y. Jung, 2017: Simulations of polarimetric, X-band radar signatures in supercells. Part I: Description of experiment and simulated $\rho_{h v}$ rings. J. Appl. Meteor. Climatol., 56, 1977-1999, https://doi.org/ 10.1175/JAMC-D-16-0138.1.

Sullivan, R. D., 1959: A two-cell vortex solution of the NavierStokes equations. J. Aerosp. Sci., 26, 767-768, https://doi.org/ 10.2514/8.8303.

Tanamachi, R. L., H. B. Bluestein, W.-C. Lee, M. Bell, and A. Pazmany, 2007: Ground-based velocity track display (GBVTD) analysis of W-Band Doppler radar data in a tornado near Stockton, Kansas, on 15 May 1999. Mon. Wea. Rev., 135, 783-800, https://doi.org/10.1175/MWR3325.1.

J. B. Houser, S. J. Frasier, and K. M. Hardwick, 2012: Mobile, X-band, polarimetric Doppler radar observations of the 4 May 2007 Greensburg, Kansas, tornadic supercell. Mon. Wea. Rev., 140, 2103-2125, https://doi.org/10.1175/MWR-D-11-00142.1. _ - _ M. Xue, W.-C. Lee, K. A. Orzel, S. J. Frasier, and R. M. Wakimoto, 2013: Near-surface vortex structure in a tornado and in a sub-tornado-strength convective-storm vortex observed by a mobile, W-band radar during VORTEX2. Mon. Wea. Rev., 141, 3661-3690, https://doi.org/ 10.1175/MWR-D-12-00331.1.

Trapp, R. J., 2000: A clarification of vortex breakdown and tornadogenesis. Mon. Wea. Rev., 128, 888-895, https://doi.org/ 10.1175/1520-0493(2000)128<0888:ACOVBA > 2.0.CO;2.

Van Den Broeke, M. S., J. M. Straka, and E. N. Rasmussen, 2008: Polarimetric radar observations at low levels during tornado life cycles in a small sample of classic southern plains supercells. J. Appl. Meteor. Climatol., 47, 1232-1247, https://doi.org/ 10.1175/2007JAMC1714.1.

Wakimoto, R. M., N. T. Atkins, and J. Wurman, 2011: The LaGrange tornado during VORTEX2: Part I: Photogrammetric analysis of the tornado combined with single-Doppler radar data. Mon. Wea. Rev., 139, 2233-2258, https://doi.org/ 10.1175/2010MWR3568.1.

, P. Stauffer, W.-C. Lee, N. T. Atkins, and J. Wurman, 2012: Finescale structure of the LaGrange, Wyoming, tornado during VORTEX2: GBVTD and photogrammetric analyses. Mon. Wea. Rev., 140, 3397-3418, https://doi.org/10.1175/MWR-D-12-00036.1.

- N. T. Atkins, K. M. Butler, H. B. Bluestein, K. Thiem, J. Snyder, and J. Houser, 2015: Photogrammetric analysis of the 2013 El Reno tornado combined with mobile X-band polarimetric radar data. Mon. Wea. Rev., 143, 2657-2683, https://doi.org/10.1175/MWR-D-15-0034.1.

_ _ and Coauthors, 2016: Aerial damage survey of the 2013 El Reno tornado combined with mobile radar data. Mon. Wea. Rev., 144, 1749-1776, https://doi.org/10.1175/MWR-D-15-0367.1.

Weber, M. E., J. Y. N. Cho, J. S. Herd, J. M. Flavin, W. E. Benner, and G. S. Torok, 2007: The next-generation multimission U.S. surveillance radar network. Bull. Amer. Meteor. Soc., 88, 1739-1752, https://doi.org/10.1175/BAMS-88-11-1739.

Weiss, C. C., H. B. Bluestein, R. Conzemius, and E. Fedorovich, 2007: Variational pseudo-multiple-Doppler wind retrieval in the vertical plane for ground-based mobile radar data. J. Atmos. Oceanic Technol., 24, 1165-1185, https://doi.org/ 10.1175/JTECH2028.1.

_ J. L. Schroeder, J. Guynes, P. Skinner, and J. Beck, 2009: The TTUKa mobile Doppler radar: Coordinated radar and in situ measurements of supercell thunderstorms during project VORTEX2. 34th Conf. on Radar Meteorology, Williamsport, VA, Amer. Meteor. Soc., 11B.2, https://ams.confex.com/ams/ 34Radar/techprogram/paper_155425.htm.

Wilson, K. A., P. L. Heinselman, C. M. Kuster, D. M. Kingfield, and Z. Kang, 2017: Forecaster performance and workload: Does radar update time matter? Wea. Forecasting, 32, 253-274, https://doi.org/10.1175/WAF-D-16-0157.1.

Wu, T., Y. Takayanagi, S. Yoshida, T. Funaki, T. Ushio, and Z. Kawasaki, 2013: Spatial relationship between lightning narrow bipolar events and parent thunderstorms as revealed by phased array radar. Geophys. Res. Lett., 40, 618-623, https://doi.org/10.1002/grl.50112.

Wurman, J., and S. Gill, 2000: Finescale radar observations of the Dimmitt, Texas (2 June 1995), tornado. Mon. Wea. Rev., 128, 2135-2164, https://doi.org/10.1175/1520-0493(2000)128<2135: FROOTD $>2.0 . \mathrm{CO} ; 2$.

_- and M. Randall, 2001: An inexpensive, mobile, rapid-scan radar. 30th Int. Conf. on Radar Meteorology, Munich, Germany, Amer. Meteor. Soc., P3.4, https://ams.confex.com/ams/30radar/ techprogram/paper_21577.htm.

_ , and C. R. Alexander, 2005: The 30 May 1998 Spencer, South Dakota, storm. Part II: Comparison of observed damage and radar-derived winds in the tornadoes. Mon. Wea. Rev., 133, 97-119, https://doi.org/10.1175/MWR-2856.1.

_ , and K. Kosiba, 2013: Finescale radar observations of tornado and mesocyclone structures. Wea. Forecasting, 28, 1157-1174, https://doi.org/10.1175/WAF-D-12-00127.1.

_ J. M. Straka, and E. N. Rasmussen, 1996: Fine-scale Doppler radar observations of tornadoes. Science, 272, 1774-1777, https://doi.org/10.1126/science.272.5269.1774.

_ , Y. Richardson, C. Alexander, S. Weygandt, and P. F. Zhang, 2007: Dual-Doppler and single-Doppler analysis of a tornadic storm undergoing mergers and repeated tornadogenesis. Mon. Wea. Rev., 135, 736-758, https://doi.org/10.1175/MWR3276.1.

, K. Kosiba, P. Markowski, Y. Richardson, D. Dowell, and P. Robinson, 2010: Finescale single- and dual-Doppler analysis of tornado intensification, maintenance, and dissipation in 
the Orleans, Nebraska, supercell. Mon. Wea. Rev., 138, 44394455, https://doi.org/10.1175/2010MWR3330.1.

and P. Robinson, 2013: In situ, Doppler radar, and video observations of the interior structure of a tornado and the wind-damage relationship. Bull. Amer. Meteor. Soc., 94, 835-846, https://doi.org/10.1175/BAMS-D-12-00114.1.

Yoshikawa, E., T. Ushio, Z. Kawasaki, S. Yoshida, T. Morimoto, F. Mizutani, and M. Wada, 2013: MMSE beam forming on fast-scanning phased array weather radar. IEEE Trans.
Geosci. Remote Sens., 51, 3077-3088, https://doi.org/10.1109/ TGRS.2012.2211607.

Yu, T.-Y., M. B. Orescanin, C. D. Curtis, D. S. Zrnić, and D. E. Forsyth, 2007: Beam multiplexing using the phasedarray weather radar. J. Atmos. Oceanic Technol., 24, 616626, https://doi.org/10.1175/JTECH2052.1.

Zrnić, D. S., and Coauthors, 2007: Agile-beam phased array radar for weather observations. Bull. Amer. Meteor. Soc., 88, 17531766, https://doi.org/10.1175/BAMS-88-11-1753. 